\title{
Wave climate in the Arctic 1992-2014: seasonality and trends
}

\author{
Justin E. Stopa ${ }^{1,2}$, Fabrice Ardhuin ${ }^{1}$, and Fanny Girard-Ardhuin ${ }^{1}$ \\ ${ }^{1}$ Univ. Brest, CNRS, IRD, Ifremer, Laboratoire d'Océanographie Physique et Spatiale (LOPS), IUEM, 29280, Brest, France \\ ${ }^{2}$ École Centrale de Nantes, 44321, Nantes, France
}

Correspondence to: Justin E. Stopa (justin.stopa@ifremer.fr)

Received: 5 February 2016 - Published in The Cryosphere Discuss.: 25 February 2016

Revised: 24 May 2016 - Accepted: 17 June 2016 - Published: 26 July 2016

\begin{abstract}
Over the past decade, the diminishing Arctic sea ice has impacted the wave field, which depends on the icefree ocean and wind. This study characterizes the wave climate in the Arctic spanning 1992-2014 from a merged altimeter data set and a wave hindcast that uses CFSR winds and ice concentrations from satellites as input. The model performs well, verified by the altimeters, and is relatively consistent for climate studies. The wave seasonality and extremes are linked to the ice coverage, wind strength, and wind direction, creating distinct features in the wind seas and swells. The altimeters and model show that the reduction of sea ice coverage causes increasing wave heights instead of the wind. However, trends are convoluted by interannual climate oscillations like the North Atlantic Oscillation (NAO) and Pacific Decadal Oscillation. In the Nordic Greenland Sea the NAO influences the decreasing wind speeds and wave heights. Swells are becoming more prevalent and windsea steepness is declining. The satellite data show the sea ice minimum occurs later in fall when the wind speeds increase. This creates more favorable conditions for wave development. Therefore we expect the ice freeze-up in fall to be the most critical season in the Arctic and small changes in ice cover, wind speeds, and wave heights can have large impacts to the evolution of the sea ice throughout the year. It is inconclusive how important wave-ice processes are within the climate system, but selected events suggest the importance of waves within the marginal ice zone.
\end{abstract}

\section{Introduction}

Sea ice plays an important role within the climate directly affecting the Earth's albedo, meridional ocean circulation, biologic ecosystems, and human activities. Satellite measure- ments from the last 30 years show Arctic ice decreased from 0.45 to 0.51 million $\mathrm{km}^{2}$ or -10.2 to $-11.4 \%$ per decade (Hartmann et al., 2013; Comiso et al., 2008). This has a dramatic impact on the sea state because there is a larger expanse of ocean available for wave development (Thomson and Rogers, 2014). Ocean waves drive the upper-ocean dynamics and influence the rich biological cycle (Tremblay et al., 2008; Popova et al., 2010). Near the Alaska coastline waves are causing erosion (Overeem et al., 2011), and as the ocean opens, connecting the Atlantic and Pacific for transportation and commerce, knowledge of the sea state becomes increasingly important (Stephenson et al., 2011; Jeffries et al., 2013).

Ice and wave interaction is a highly coupled two-way system. On the one hand, sea ice defines the shape and size of the basin controlling the available fetch; on the other hand, waves break up ice (Marko, 2003). The warming in the past decade decreased sea ice cover (Zhang, 2005; Steele et al., 2008; Screen and Simmonds, 2010; Cavalieri and Parkinson, 2012; Frey et al., 2015). A model simulation of Wang et al. (2015) and data from altimeters in Francis et al. (2011) show that more open water in the Beaufort and Chukchi seas increased wave heights. The objective of this study is to describe the wave climate poleward of $66^{\circ} \mathrm{N}$ since the Arctic wave climate has been less investigated compared to studies of sea ice extent. This provides an opportunity to describe the Arctic as a complete system and relate our results to existing regional studies in the Nordic seas (Semedo et al., 2014), the Nordic and Barents seas (Reistad et al., 2011), and BeaufortChukchi seas (Francis et al., 2011; Wang et al., 2015) .

Analysis of historical wave observations including insitu buoy measurements (e.g., Gemmrich et al., 2011), remotely sensed waves from altimeters (e.g., Zieger et al., 2009), observations from voluntary observing ships 
(e.g., Gulev and Grigorieva, 2006), and microseisms (e.g., Husson et al., 2012) give us useful information about the wave climate. Still, in the Arctic these sources are not entirely satisfactory. Therefore, we use WAVEWATCH III of (called WW3 herein) Tolman and the WAVEWATCH III Development Group (2014) to provide detailed wave conditions. Ice concentrations derived from the Special Sensor Microwave Imager (SSM/I) are the longest time series from 1992 to present and have the highest resolution of $12.5 \mathrm{~km}$. This time period coincides with available altimeters so we focus on describing the wave climate for 1992-2014 with both the altimeters and the wave model.

The study is organized as follows. We provide background information regarding the model setup, input wind and ice fields, altimeter wave data, and our analysis methodology in Sect. 2. Section 3 focuses on validating our wave modeling efforts using wave heights from altimeters. Next we describe the wave climate in Sect. 4, illustrating the seasonality, extreme conditions, and trends of the wave field over the last 23 years. In Sect. 5 we demonstrate the importance of waveice interaction through selected wave events. Finally, we discuss the results and give our conclusions in Sects. 6 and 7, respectively.

\section{Data sets, model implementation, and methodology}

The Arctic Ocean is smaller in scale compared to other oceans: $7000 \mathrm{~km}$ at its widest point. The ocean is surrounded by a continental shelf with depths of $300 \mathrm{~m}$. The center of the basin near the North Pole has depths greater than $4000 \mathrm{~km}$ and is often ice covered. The combination of ice coverage and geography creates the different regional seas shown in Fig. 1. We will distinguish seven sub-regions: (1) Nordic Greenland Sea, (2) Barents Sea, (3) Kara Sea, (4) Laptev Sea, (5) East Siberia Sea, (6) Beaufort-Chukchi seas, and (7) Baffin Bay. The following subsections describe the ice concentrations, wind reanalysis, satellite altimetry, model setup, and analysis techniques.

\subsection{Ice concentration from IFREMER/CERSAT (SSM/I)}

Satellite-derived ice concentrations are an invaluable data source to observe ice dynamics (e.g., Frey et al., 2015). The SSM/I brightness temperatures accurately estimate sea ice concentration (e.g., Liu and Cavalieri, 1998). The ASI algorithm of Kaleschke et al. (2001) uses a transfer equation that relates the polarization difference to ice concentration. High-frequency channels of SSM/I are used to estimate a daily average on a $12.5 \mathrm{~km}$ grid at IFREMER/CERSAT and describe important spatial features of the marginal ice zone (MIZ) (Ezraty et al., 2007). Figure 2 shows the minimum ice extent and total ice area for the period 1992-2014. The time series in the left panel confirms the continual decrease in ice

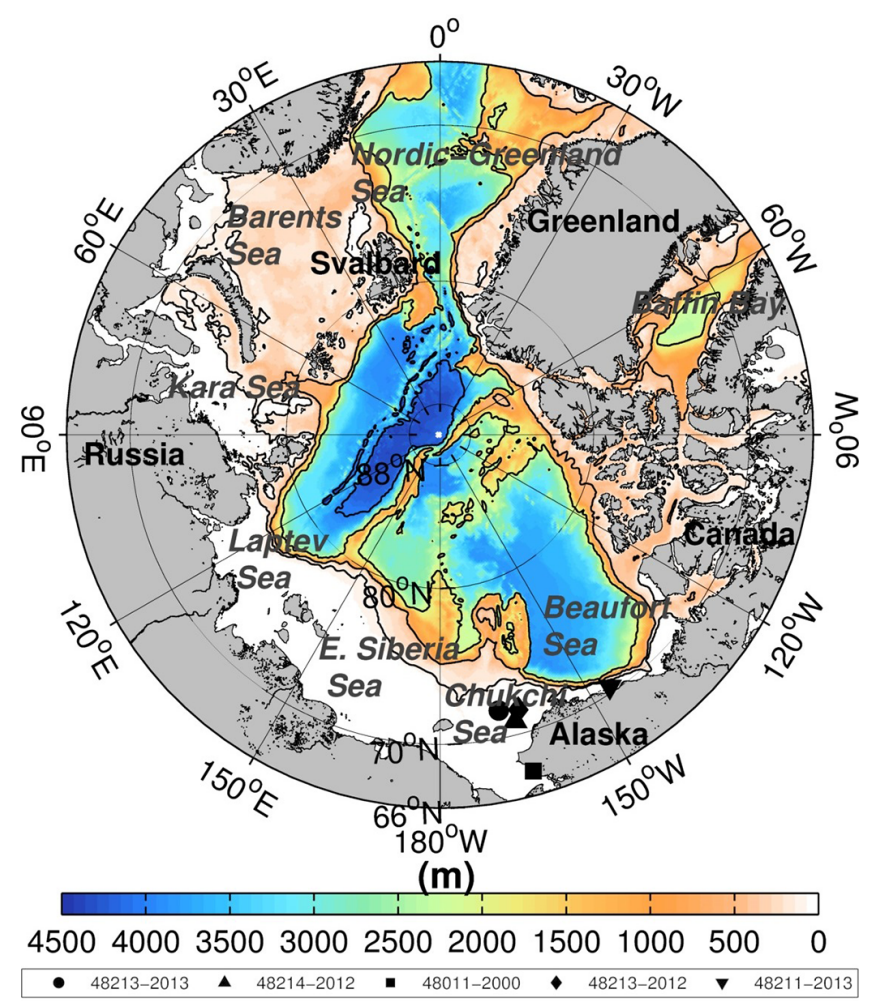

Figure 1. Regional seas of the Arctic Ocean with bathymetry (color), buoy locations (black symbols), and 4000, 2000, 500, and $100 \mathrm{~m}$ depth contours (black lines).

coverage. The minimum sea ice coverage is occurring later in September from 1992 to 2014 with some decadal variability and/or anomalous years of 1997 and 2006. The sea ice is stable for 1992-2002. Following this period there is an accelerated reduction in sea ice extent with the ice minimum occurring in 2012. The right panel shows the spatial view of the ice edge minimum from the years 1992 to 2002, 2002, 2007, and 2012. The East Siberia, Chukchi, and Beaufort seas have the largest changes in ice cover so we expect increasing waves.

\subsection{Reanalysis wind fields}

Wave hindcasts using wind reanalysis data sets have successful applications including the National Center for Environmental Prediction (NCEP) Climate Forecast System reanalysis (CFSR) (Chawla et al., 2013; Rascle and Ardhuin, 2013; Stopa and Cheung, 2014). The important advancements of CFSR with respect to predecessors Reanalysis I and II consist of coupling between the ocean, atmosphere, land surface, and sea ice model, assimilation of satellite radiances, and increased horizontal and vertical resolution in the atmospheric model (Saha et al., 2010, 2014). The atmospheric model has a resolution of approximately $0.3^{\circ}(37 \mathrm{~km})(\mathrm{v} 2$ has $\left.0.2^{\circ} 23 \mathrm{~km}\right)$ and assimilates data in three dimensions. 


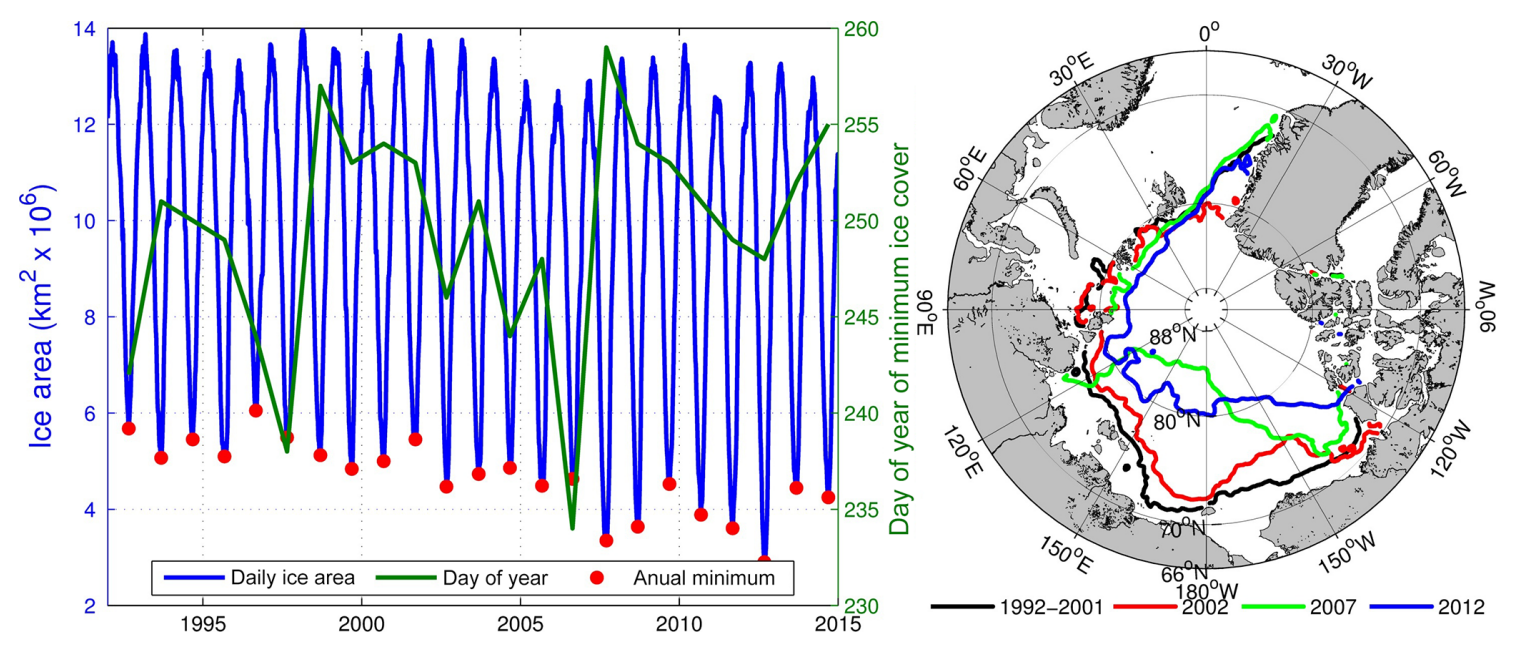

Figure 2. SSM/I Ifremer CERSAT ice concentrations 1992-2014. The left panel displays the ice coverage in the area, assuming for grid points with a concentration greater than $15 \%$ (blue) and minimum of the day of the year (green). The right panel shows the minimum spatial ice edge defined by the $15 \%$ ice concentration contour for 1992-2001 (median), 2002, 2007, and 2012.

Wind speeds at $10 \mathrm{~m}$ elevation (U10) are available hourly. In addition, the wave reanalysis of the European Centre for Medium-range Weather Forecasts (ECMWF) ERA-Interim (ERAI), which couples the atmosphere and wave model and assimilates altimeter wave data, has improved performance over its predecessor ERA-40 (Dee et al., 2011). ERAI has a spatial resolution of $0.7^{\circ}$ with wind every $6 \mathrm{~h}$. The wave reanalysis couples the wave and atmosphere models while assimilating wave data from altimeters (Dee et al., 2011). The data set is consistent in time and does not have the same discontinuous features as CFSR; however, it is not able to resolve the upper percentiles (Stopa and Cheung, 2014).

It is not evident whether CFSR or ERAI is better suited to drive a wave model in the Arctic. Therefore a concurrent hindcast from 2010 to 2014 is used to assess the wind forcing differences on the wave field. Appendix A gives a detailed description of the results summarized here. The largest differences are in the upper percentiles and ERAI significantly underestimates the extreme wave heights. In short, the model errors mirror those of the global basin (Stopa and Cheung, 2014). Due to the importance of resolving the extremes, we use CFSR to re-create the waves from 1992 to 2014.

\subsection{Significant wave heights from altimeters}

Altimeter data have provided an ample source of global wave observations and aided in the development and evaluation of spectral wave models (e.g., Chen et al., 2002; Ardhuin et al., 2010; Stopa et al., 2015). Significant wave heights $\left(H_{\mathrm{s}}\right)$ are measured from active microwave sensors typically in the $\mathrm{Ku}$ or $\mathrm{Ka}$ bands under all atmospheric conditions. Once the data are quality controlled and sensor biases are removed, $H_{\mathrm{s}}$ errors are comparable to buoy measurements (Zieger et al., 2009; Sepulveda et al., 2015). We use the merged and calibrated data set of Queffeulou and
Croize-Fillon (2016). The reprocessed wave measurements from European Remote Sensing satellites 1 and 2 (ERS1, ERS2), Environmental Satellite (ENVISAT), Geosat FollowOn, CRYOSAT2, and Altika SARAL are used throughout this study. The northern latitude limit is $81.4^{\circ} \mathrm{N}$ for Geosat Follow-On, $82^{\circ} \mathrm{N}$ for ERS1, ERS2, ENVISAT, and SARAL, and $88^{\circ} \mathrm{N}$ for CRYOSAT2. The repeat track cycle is 17 days for Geosat Follow-On, 35 days for ERS1, ERS2, ENVISAT, and SARAL, and 369 days for CRYOSAT2. The merged data set spans the duration of the hindcast (1992-2014).

\subsection{WAVEWATCH III model implementation and wave-ice dissipation}

WAVEWATCH III of Tolman et al. (2013) is a communitybased spectral wave model (Tolman and the WAVEWATCH III Development Group, 2014). WW3 evolves the wave action equation in space and time, with discretized wave numbers and directions. Conservative wave processes, represented by the local rate of change and spatial and spectral transport terms are balanced by the nonconservative sources and sinks. We implement version 5.08 of WW3, on a curvilinear grid matching the spatial resolution of ice concentrations at $12.5 \mathrm{~km}$. The curvilinear grid is well suited to model waves near the poles since the geographic distance between nodes is equal making the computation more efficient (Rogers and Orzech, 2013). The spectra are composed of 24 directions and 32 frequencies exponentially spaced from 0.037 to $0.7 \mathrm{~Hz}$ at a relative increment of 1.1 . The reanalysis winds are linearly interpolated to the wave model grid. We use WW3's third-order Ultimate Quickest scheme by Tolman (2002) with the garden sprinkler correction. Global $0.5^{\circ}$ resolution hindcast of Rascle and Ardhuin (2013) provides the spectral boundary conditions along $66^{\circ} \mathrm{N}$. 

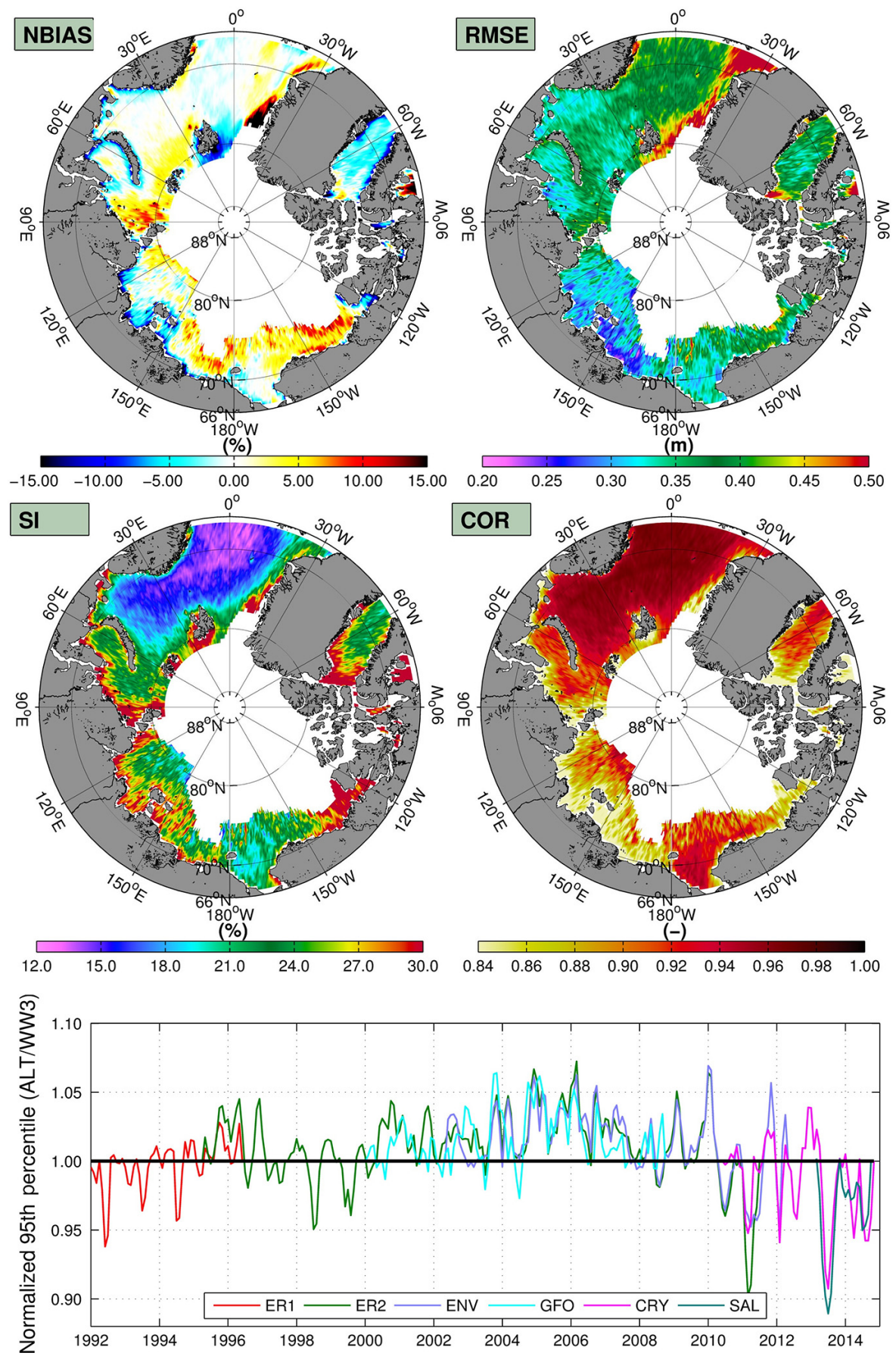

Figure 3. Top four panels display the normalized bias (NBIAS), root-mean-square error (RMSE), scatter index (SI), and correlation coefficient (COR) for collocated $H_{\mathrm{S}}$ for the CFSR wave hindcast and the merged altimeters 1992-2014. The bottom panel displays the normalized monthly $H_{\mathrm{S}}$ 95th percentile for each satellite platform: European Remote Sensing satellites 1 and 2 (ER1, ER2), Environmental Satellite ENVISAT (ENV), Geosat Follow-On (GFO), CRYOSAT2 (CRY), and Altika SARAL (SAL).

The source terms of Ardhuin et al. (2010) describes the wave physics, which performs well in terms of $H_{\mathrm{s}}$, average wave periods, and partitioned wave quantities (Stopa et al., 2015). The wind-wave growth parameter $\beta_{\max }$ is set to 1.25 and otherwise we use the same settings as Rascle and Ard- huin (2013). Due to the importance of wave-ice interactions, a new source term is developed and implemented in WW3 to describe wave dissipation under ice. The dissipation is modeled by a laminar to turbulent boundary layer based on a critical Reynolds number computed from the orbital wave ve- 

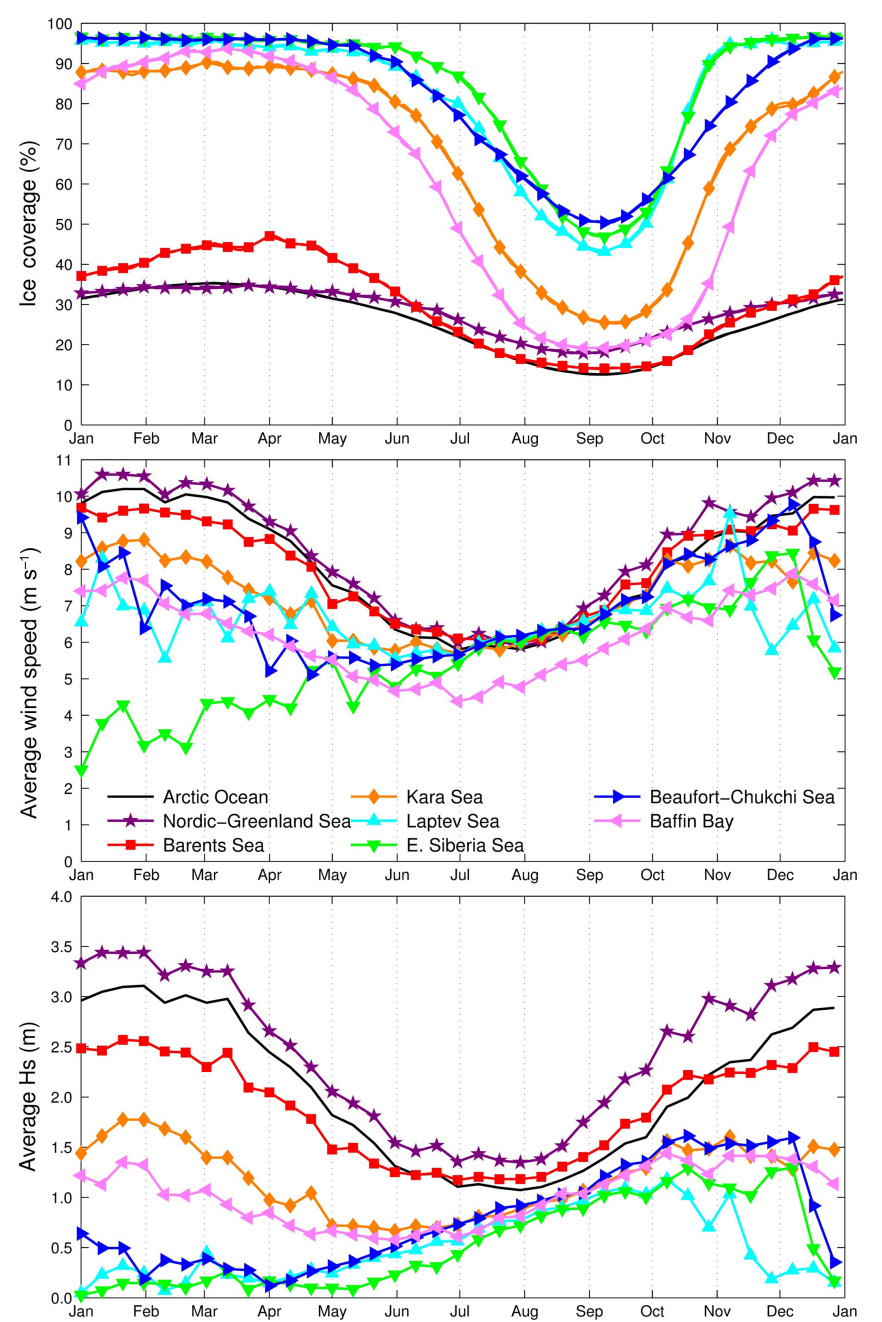

Figure 4. Ice coverage (top), wind speed (middle), and $H_{\mathrm{S}}$ daily averages computed from a spatial average for each Arctic region showing the seasonality.

locity. This parameterization was calibrated using Wadhams and Doble (2009) data set but still remains somewhat poorly constrained. A full description of the formulation is given in Appendix B.

\subsection{Wave parameters and analysis techniques}

The wave climate is described using the total significant wave height $\left(H_{\mathrm{s}}\right)$ defined as $H_{\mathrm{s}}=4 \sqrt{m 0}$ where $m 0$ is the zeroth moment $(p=0)$ of the spectrum $(E(f))$ $\left(m_{p}=\int_{0}^{\infty}(2 \pi f)^{p} E(f) \mathrm{d} f\right)$, mean wave period $(T m 02=$ $\sqrt{m 0 / m 2}$ ), and average direction $\left(\theta_{m}\right)$. The mean wave period has reduced variability compared to other wave period definitions (i.e., peak period or $\sqrt{m-1 / m 0}$ ) since it is calculated from the second moment of the wave spectrum. Swells characterized by longer wavelengths propagate considerable distances under sea ice while high-frequency waves are scattered and dissipated near the ice edge (Kohout et al., 2014; Li et al., 2015; Ardhuin et al., 2015). Therefore the wind seas $\left(H_{\mathrm{sw}}, \theta_{\mathrm{mw}}\right)$ and swells $\left(H_{\mathrm{ss}}, \theta_{\mathrm{ms}}\right)$ are analyzed separately by partitioning wave spectra using the Hanson and Phillips (2001) method. According to Pierson and Moskowitz (1964) the sea state can be classified as wind sea when the wave age (WA) or ratio of peak phase speed $C_{\mathrm{p}}$ to wind speed is $\mathrm{WA}=C_{\mathrm{p}} / \mathrm{U} 10<1.2$ and as swell when WA $>1$.2. Semedo et al. (2011) and Semedo et al. (2014) demonstrated the practicality of this classification through the probability of having a swell-dominated wave field (swell persistence): $P_{\mathrm{s}}=P\left(C_{\mathrm{p}} / \mathrm{U} 10>1.2\right)=N_{\mathrm{s}} / N_{\text {total }}$, where $N_{\mathrm{s}}$ is the number of swell-dominated events and $N_{\text {total }}$ is the total number of events.

In seas with varying ice cover, the method to describe wave statistics is important (Tuomi et al., 2011). We base our statistics on ice-free conditions (ice concentration $<15 \%$ ), but other statistics can be interrelated through the sea ice probability shown in Appendix C. Our results are calculated using the $3 \mathrm{~h}$ model output for the hindcast duration. $H_{\mathrm{s}}$ percentiles are calculated from the ice-free statistics and the matching $H_{\mathrm{s}}$ index is used to identify corresponding wave periods and directions. $\mathrm{A} \pm 0.2 \mathrm{~m}$ bounds of the associated $H_{\mathrm{s}}$ index is used to average the wave periods and directions. This approach gives a more accurate physical description of the events (Anderson et al., 2015). We compute trends using Sen's method and test for statistical significance with the Mann-Kendall test. This method is a non-parametric technique and a robust way of computing trends since it can handle missing data and is less influenced by outliers (Mann, 1945; Kendall, 1975; Sen, 1968). We account for the seasons using the adaptation of Hirsch et al. (1982) and used in wave climatology studies by Wang and Swail (2001), Young et al. (2011), and Stopa and Cheung (2014). We compute trends from monthly statistics and require that the time series be ice free for at least 10 years.

\section{Wave hindcast validation}

Before the wave climate is assessed we validate the hindcast using the merged altimeter data set for 1992-2014. Altimeter-model co-locations are found using the nearest neighbor within $6 \mathrm{~km}$ and $30 \mathrm{~min}$. A running mean of 5 points smooths the satellite tracks to make the spatial and temporal scales comparable. The top 4 panels of Fig. 3 show four complementary $H_{\mathrm{s}}$ statistics computed in $25 \mathrm{~km}$ bins. There is minimal bias for the majority of the domain; however, some errors exist. In the Baffin Bay and the region north of Svalbard there is an underestimation of 5 and $10 \%$, respectively. Otherwise spurious negative biases are located near the coasts. In the Beaufort, Chukchi, and Laptev seas the model overestimates the wave heights by $5-10 \%$. The root-mean-square errors (RMSEs) are commonly less than $0.4 \mathrm{~m}$. East of Greenland has the largest RMSE of $0.5 \mathrm{~m}$. This area has considerable ice displacements within 1 day 

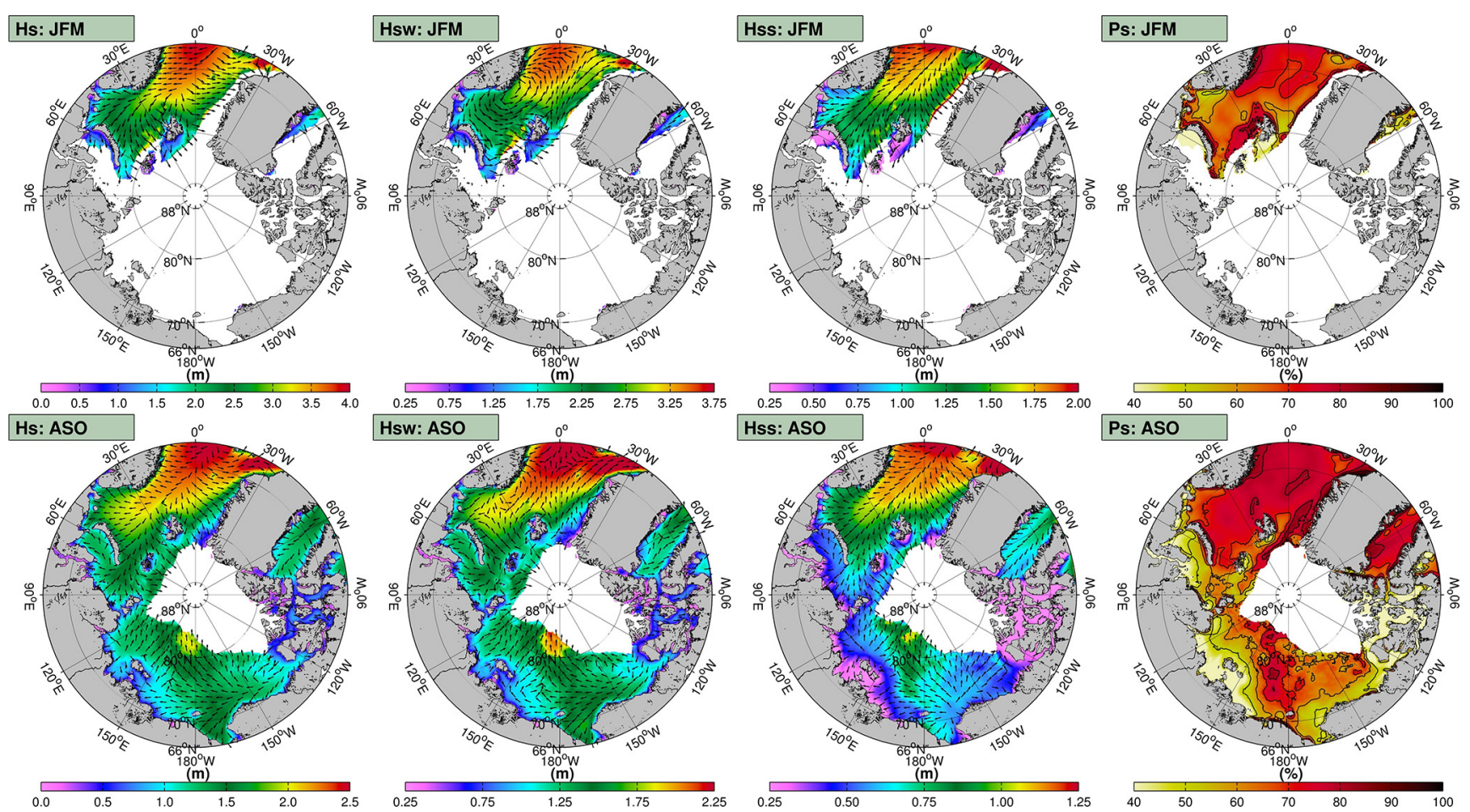

Figure 5. January-February-March (JFM) and August-September-October (ASO) seasonal averages of $H_{\mathrm{S}}$ (first column), wind-sea wave height $H_{\mathrm{sW}}$ (second column), swell wave height $H_{\mathrm{ss}}$ (third column), and swell persistence $P_{\mathrm{S}}$ (fourth column). The directions are computed from by averaging the east-west and north-south components separately.

and the SSM/I daily input might not be able to resolve the rapid change. The Nordic Greenland Sea is mostly ice free year round and thus has the lowest scatter indices (12\%), suggesting the model performs well in the absence of sea ice, in contrast to the coastal regions of the Baffin Bay, Kara, Laptev, and Beaufort seas that have considerable ice variability and create the largest scatter indices of $30 \%$. The model and altimeters are highly correlated with coefficients larger than 0.95. The lowest correlations occur in the Laptev, East Siberia, and East Beaufort seas. These regions have small wave heights and result in small biases and RMSEs.

The bottom panel of Fig. 3 shows the consistency of hindcast using the monthly 95th percentile for each satellite mission. The 95 th percentile is a rigorous test because it is difficult to resolve extreme waves. The average and median are verified to have no distinct trends (not shown). There is a slight decreasing trend in recent years but it is inconclusive whether this trend will continue and is contrary to the global increase observed by Rascle and Ardhuin (2013) for 20062011. There are annual variations but the hindcast is relatively consistent in time, making it applicable for climate studies with no noticeable discontinuous features.

\section{Wave climate}

\subsection{Seasonality}

The Arctic Ocean experiences a dramatic seasonal change. Daily spatial averages of the seven regions in Fig. 1 generalize sea ice, wind speed, and wave seasonality in Fig. 4. Two different classifications are identified by the seasonal ice cover. The Nordic Greenland and Barents seas have small seasonal variation while large seasonal changes occur in the Baffin Bay, Beaufort-Chukchi, East Siberia, Laptev, and Kara seas. All regions have an ice minimum in early September. The wind forcing follows a sinusoid for all seas except the East Siberia Sea with a maximum in January and minimum in July. In the regions with reduced ice cover, like the Nordic Greenland and Barents seas, the waves mirror the wind. Wave heights in the Baffin Bay and Kara Sea, which remain $10 \%$ ice free from November to July, follow the winds and can be described by a sinusoid. In the Beaufort-Chukchi, East Siberia, and Laptev seas the wave seasons are skewed with an annual maximum in October. The antisymmetric seasonal cycle is created by the increasing wind speeds coupled with partially ice-free seas in September and October. Due to the relative difference between the ice and wind we define the winter season as January-February-March (JFM) and the summer season as August-September-October (ASO). 

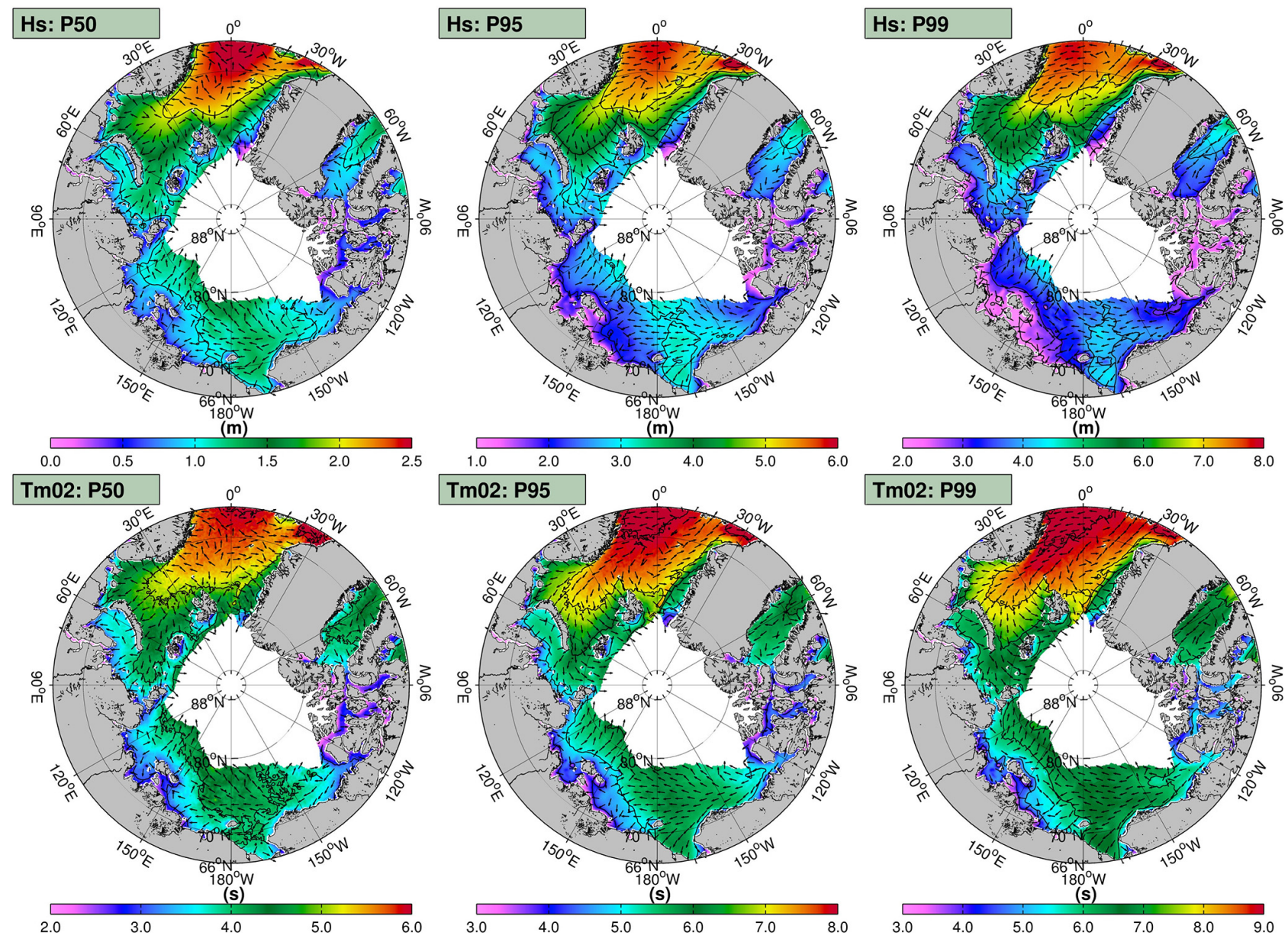

Figure 6. Significant wave height percentiles (top panels) and corresponding averaged wave periods (bottom panels) and directions (arrows).

Figure 5 presents the wave conditions for the two extreme seasons: JFM and ASO. The sea state is described through the $H_{\mathrm{s}}, H_{\mathrm{sw}}, H_{\mathrm{ss}}$, and $P_{\mathrm{s}}$. In JFM, only the Nordic Greenland, and Barents seas are ice free. Waves generated in the North Atlantic propagate into these seas with a sheltering in the Barents Sea. In JFM, the Nordic Greenland Sea has the tallest wave heights of the Arctic. The wind seas follow the driving winds and are characterized by cyclonic (anticlockwise) circulation, a characteristic of the North Atlantic sub-basin (Sterl and Caires, 2005; Semedo et al., 2014). The resulting wind-sea wave heights exceed $3.5 \mathrm{~m}$ while the swell wave heights are smaller and travel from the southwest. The top right panel shows swells persist $70 \%$ of the time, which is consistent with open ocean conditions where wind seas and swells are ubiquitous (Chen et al., 2002).

In ASO, ice coverage is minimum and waves are generated across the Arctic. The $H_{\mathrm{s}}$ pattern in the Nordic, Greenland, and Barents seas is similar to JFM with only a reduction in magnitude. The semi-enclosed seas have smaller $H_{\mathrm{s}}$ (commonly less than $1.5 \mathrm{~m}$ ) than the Nordic Greenland Sea. There are distinct regional characteristics of the wind seas and swells. The cyclonic structure of the wind seas near Norway in JFM is not clearly visible in ASO. The swell mean wave directions follow the same pattern as JFM in the Nordic Greenland and Barents seas and propagate from the Atlantic northward into the sea ice. In the Laptev and East Siberia seas the wind seas and swells are directed into the sea ice with an Easterly component. $H_{\mathrm{sw}}$ and $H_{\mathrm{ss}}$ have local maxima located near $\left(170^{\circ} \mathrm{E}, 77^{\circ} \mathrm{N}\right)$ where the easterly waves are able to sufficiently develop. In the Beaufort Sea the wind sea and swell mean wave directions flow from the southeast. In the East Beaufort Sea $\left(135^{\circ} \mathrm{E}, 74^{\circ} \mathrm{N}\right)$, there is a subtle anti-cyclonic (clockwise) structure in the wind seas while the swell mean wave directions are opposite and flow from the west. In the narrow corridor of the Baffin Bay, the wind sea and swell mean wave directions are opposite and represent different phases of passing storms. The bottom right panel shows the swell persistence is $>85 \%$ and exceeds $95 \%$ in the Nordic Greenland, Barents seas, and Baffin Bay due to their exposure to the swells generated in the North Atlantic. In the semi-enclosed seas like the Kara, Laptev, East Siberia, 

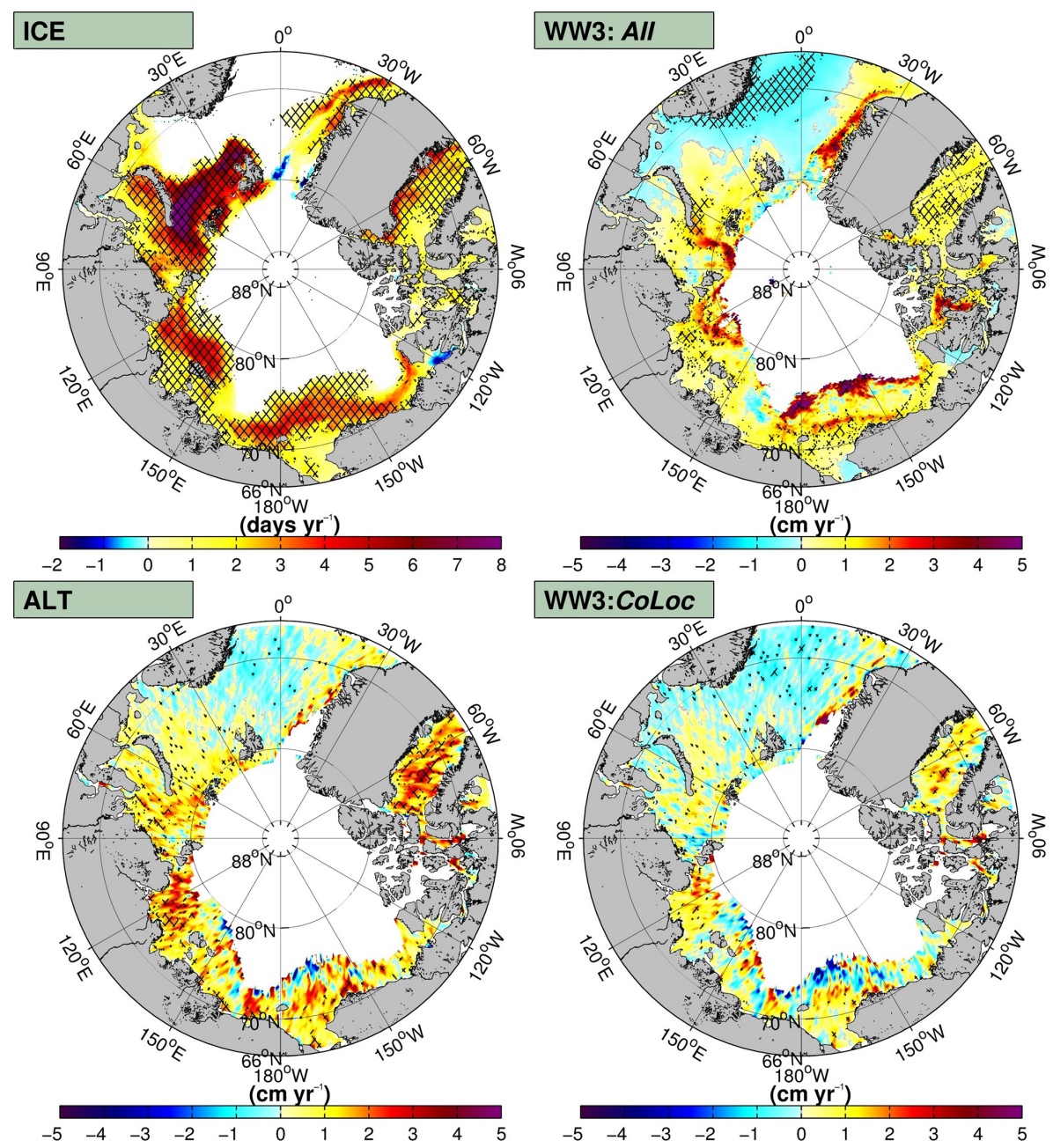

Figure 7. Ice coverage and $H_{\mathrm{S}}$ trends given by Sen's slope with the Mann-Kendall test (thatched areas). The top left panel displays the trend of the annual number of ice-free days per year (ICE). The other panels show the trends of monthly averaged $H_{\mathrm{S}}$ data sets: using the entire $3 \mathrm{~h}$ hindcast (top right: All), altimeters (bottom left: ALT), and co-located hindcast (bottom right: CoLoc) given in $\mathrm{cm}^{-1} \mathrm{rar}^{-1}$.

Beaufort, and Chukchi there is an equal proportion of wind waves and swells (40-60\%).

\subsection{Percentiles}

$H_{\mathrm{S}}$ percentiles are a useful to way to describe the sea state statistical distribution (e.g., Stopa et al., 2013a, b). Figure 6 shows the 50th (median), 95th, and 99th $H_{\mathrm{s}}$ percentiles with matching wave directions and mean periods. The statistics have a consistent spatial pattern due to the geographic shape of the basin. The most prominent feature is the maximum located in the Nordic Greenland Sea for all percentiles. Here the median $H_{\mathrm{s}}$ exceeds $2.5 \mathrm{~m}$ and corresponding $T m 02$ is $6 \mathrm{~s}$. In the rest of the basin the $H_{\mathrm{s}}$ median is commonly $1.5 \mathrm{~m}$ with reduction near the coasts. The 95th $H_{\mathrm{s}}$ percentile exceeds $5.5 \mathrm{~m}$ with $T m 02$ of $8 \mathrm{~s}$ in the Nordic Greenland Sea. In the Laptev, East Siberia, Chukchi, and Beaufort seas the 95th $H_{\mathrm{s}}$ percentiles are $2.5 \mathrm{~m}$ with $\operatorname{Tm} 02$ of $6 \mathrm{~s}$. The $H_{\mathrm{s}}$ and
T $m 02$ at the 99th percentile exceed $8 \mathrm{~m}$ and $9 \mathrm{~s}$ in the Nordic Greenland Sea while in the Laptev, East Siberia, Chukchi, and Beaufort seas are reduced with $4 \mathrm{~m}$ and $6.5 \mathrm{~s}$.

The corresponding wave directions found by using matching indices of the $H_{\mathrm{s}}$ give an indication of the wind sea and swell events. The median is a mix of numerous wave conditions and thus less representative of distinct wind sea and swell events. In the Beaufort-Chukchi seas the wave directions of the 50th percentile are focused into the sea ice while for the 95th and 99th percentiles the wave directions flow from the east parallel to the ice edge. Due to the geometry of the Beaufort-Chukchi seas, the largest fetch occurs when the wind is parallel to the ice edge. The wave directions of the 95th and 99th percentiles contain similar patterns as the seasonal components of Fig. 5. For example the region near East Greenland is characterized by waves from the north as seen in the wind seas while the waves offshore of Norway are directed from the south typical of swells in JFM. In the 



Figure 8. Sen's slope with the Mann-Kendall test (thatched areas) for monthly averaged wind speeds (U10) (top left), wind-sea wave heights $\left(H_{\mathrm{sw}}\right)$ (top center), swell wave heights $\left(H_{\mathrm{Ss}}\right)$ (top right), average wave period $(T m 02)$ (bottom left), wind-sea steepness $\left(\mathrm{ST}_{\mathrm{W}}\right)($ bottom center), and wave age (WA) (bottom right) from the wave hindcast in percentage per year relative to the average.

Table 1. Correlation coefficients and trends for the various regions and parameters. The correlations coefficients are given between areaaveraged monthly time series versus the North Atlantic Oscillation and the Pacific Decadal Oscillation in parentheses. Statistically significant results are given by the $*$ when the $p$ value is less than 0.05 .

\begin{tabular}{lccccc}
\hline Region & Avg ocean area & $\mathrm{U} 10_{\text {Avr }}$ & $\mathrm{U} 10 \mathrm{P} 95$ & $H_{\mathrm{SAvr}}$ & $H_{\mathrm{SP} 95}$ \\
\hline Arctic Ocean & $-0.19^{*}\left(-0.25^{*}\right)$ & $+0.37^{*}(-0.0)$ & $+0.35^{*}(-0.08)$ & $+0.31^{*}(-0.02)$ & $+0.31^{*}(-0.08)$ \\
Nordic Greenland Sea & $-0.10\left(-0.27^{*}\right)$ & $+0.37^{*}(-0.09)$ & $+0.35^{*}(-0.11)$ & $+0.32^{*}(-0.08)$ & $+0.33^{*}\left(-0.13^{*}\right)$ \\
Barents Sea & $-0.15^{*}\left(-0.33^{*}\right)$ & $+0.29^{*}(-0.10)$ & $+0.29^{*}\left(-0.12^{*}\right)$ & $+0.22^{*}(-0.04)$ & $+0.22^{*}(-0.10)$ \\
Kara Sea & $-0.15^{*}\left(-0.16^{*}\right)$ & $+0.19^{*}\left(-0.20^{*}\right)$ & $+0.16^{*}\left(-0.20^{*}\right)$ & $+0.11(-0.10)$ & $+0.05\left(-0.14^{*}\right)$ \\
Laptev Sea & $+0.15\left(-0.27^{*}\right)$ & $-0.01(-0.11)$ & $-0.01(-0.09)$ & $-0.12(+0.06)$ & $-0.08(+0.01)$ \\
E. Siberia Sea & $+0.17(-0.13)$ & $+0.01(-0.08)$ & $+0.02(-0.06)$ & $-0.12(+0.14)$ & $-0.01(+0.13)$ \\
Beaufort-Chukchi seas & $-0.03\left(-0.24^{*}\right)$ & $+0.05\left(-0.21^{*}\right)$ & $-0.00\left(-0.21^{*}\right)$ & $+0.05(-0.15)$ & $+0.00\left(-0.17^{*}\right)$ \\
Baffin Bay & $-0.12\left(-0.19^{*}\right)$ & $-0.07\left(-0.16^{*}\right)$ & $-0.09\left(-0.15^{*}\right)$ & $+0.10(-0.11)$ & $+0.08(-0.13)$ \\
\hline
\end{tabular}




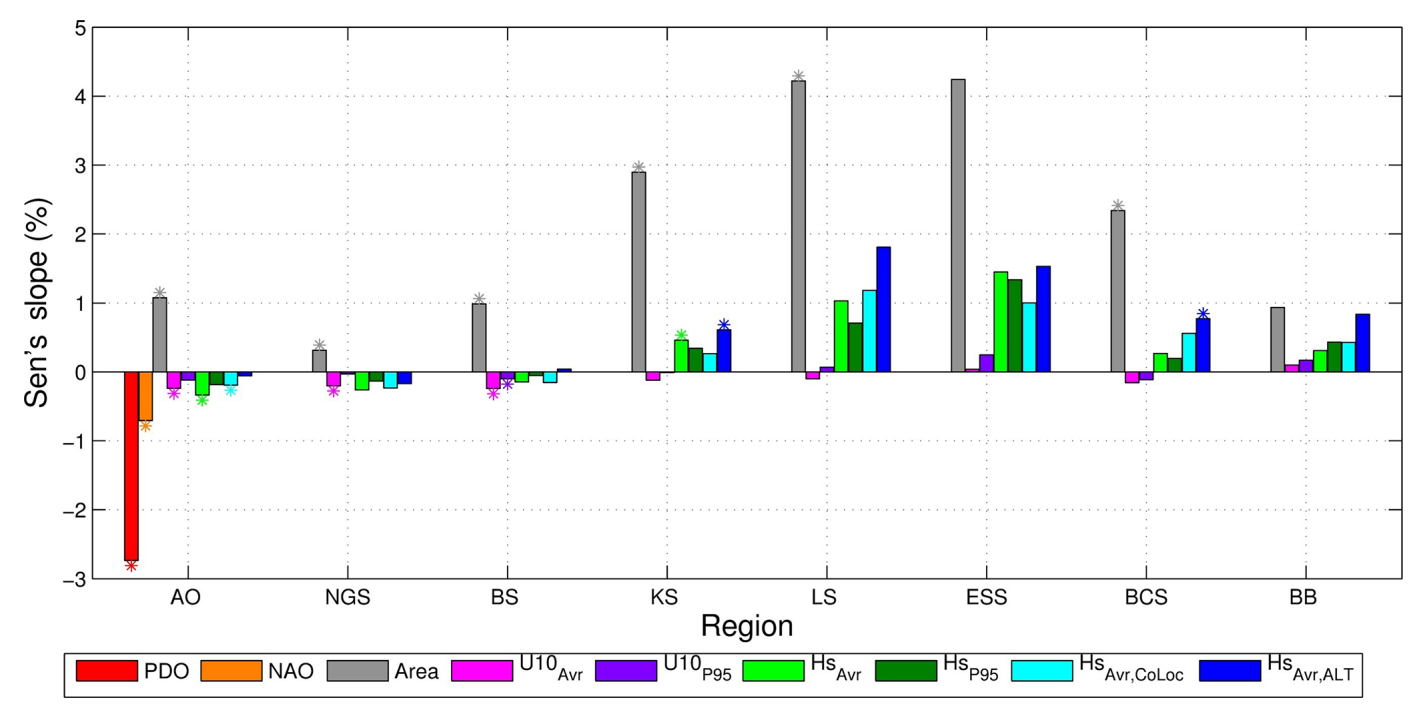

Figure 9. Sen's slope with the Mann-Kendall test (denoted by a *) for the Arctic regions of the Arctic Ocean (AO), Nordic Greenland Sea (NGS), Barents Sea (BS), Kara Sea (KS), Laptev Sea (LS), East Siberia Sea (ESS), Beaufort-Chukchi seas (BCS), and the Baffin Bay (BB) from monthly time series of the North Atlantic oscillation (NAO), Pacific Decadal Oscillation (PDO), ocean area (Area), wind speed (U10), significant wave heights from the $3 \mathrm{~h}$ model data $\left(H_{\mathrm{s}}\right.$ Avr and $H_{\mathrm{s}}$ P95 $)$, and co-located model and altimeter data $\left(H_{\mathrm{s}}\right.$ Avr, CoLoc, $H_{\mathrm{s}}$ Avr, ALT $)$.

Beaufort, Chukchi, and East Siberia seas, the waves from the east are common to both the wind waves and swells in JFM and ASO.

\subsection{Trends}

With the reduction of sea ice cover, wave heights are expected to increase. Figure 7 shows Sen's slope computed from monthly averaged quantities with the seasonal MannKendall test for ice coverage and $H_{\mathrm{s}}$ from altimeters and the model. The top left panel displays the trend of the SSM/I ice concentrations in number of days per year that are ice free (i.e., concentration $<15 \%$ ). Most of the ice-covered areas are statistically significant and are ice free on 2 additional days each year. The strongest trends are located in the Barents and Kara seas with 8 more ice-free days per year. The isolated regions near Svalbard, Greenland, and the Amundsen Gulf have increasing ice coverage.

Most of the basin has increasing wave heights shown by the altimeters and wave model in the top right and bottom panels. The bottom panels show that the co-located $H_{\mathrm{S}}$ trends from the altimeters and the model agree, despite the stronger trends in the altimeters. However, the altimeter confidence interval encompasses the model results so statistically they are equivalent. This is a verification that the CFSR forcing is homogeneous throughout this time period. Discrete satellite passes do not capture the complete space-time history, causing spurious trends especially near the MIZ in the East Siberia and Beaufort seas. The trends computed from the continuous hindcast in the top right panel show a spatially consistent pattern. The ice variability is expected to cause the discrepancies in the East Siberia and Beaufort-
Chukchi seas that exist comparing the top and bottom panels. The Nordic Greenland Sea is the only region with a consistent statistically significant decreasing trend shown in the top right panel. In the Beaufort-Chukchi seas, our rates of $1.5 \mathrm{~cm} \mathrm{year}^{-1}$ are in agreement with Francis et al. (2011), who estimated a trend of $2 \mathrm{~cm}_{\text {year }}{ }^{-1}$. Wang et al. (2015) estimated trends on the order of $40 \mathrm{~cm}$ computed by the difference between 1970-1991 and 1992-2013. Assuming a linear rate spanning the 23-year period, our rate equates to a 35 $\mathrm{cm}$ increase. Some extreme trends greater than $4 \mathrm{~cm}_{\text {year }}{ }^{-1}$ exist in the Baffin Bay and Laptev Sea and are statistically significant using the merged altimeters. These rates are large compared to the global calculations of Young et al. (2011), who estimated the largest trends to be $2 \mathrm{~cm}_{\text {year }}{ }^{-1}$.

Figure 8 shows the Sen's slope computed from other monthly averaged parameters. The rates are presented as percentages relative to the mean to allow comparison. The trends in U10 are calculated using the entire data set independent of ice cover; otherwise all other variables are computed from ice-free statistics. The decreasing U10 trend in the Nordic Greenland Sea is significant and is consistent with the $H_{\mathrm{S}}$ trend. Across most of the sea ice, U10 is decreasing especially in the Beaufort Sea. Some regions have weak increasing trends of $0.25 \%$ per year. Wind speeds in the Baffin Bay are increasing creating taller wave heights.

The $T m 02$ trends follow the same pattern as the wave heights in Fig. 7 and with an increase of 2\% (2-3cs) per year. The $H_{\mathrm{sw}}$ and $H_{\mathrm{ss}}$ trends have similar spatial patterns as $H_{\mathrm{s}}$. However, $H_{\mathrm{ss}}$ is increasing at a faster rate compared to $H_{\mathrm{sw}}$ in the Beaufort, East Siberia, Laptev, and Kara seas. This increase is directly related to the higher occurrence of swells (i.e., WA is increasing). The decrease in $H_{\mathrm{ss}}$ in the 

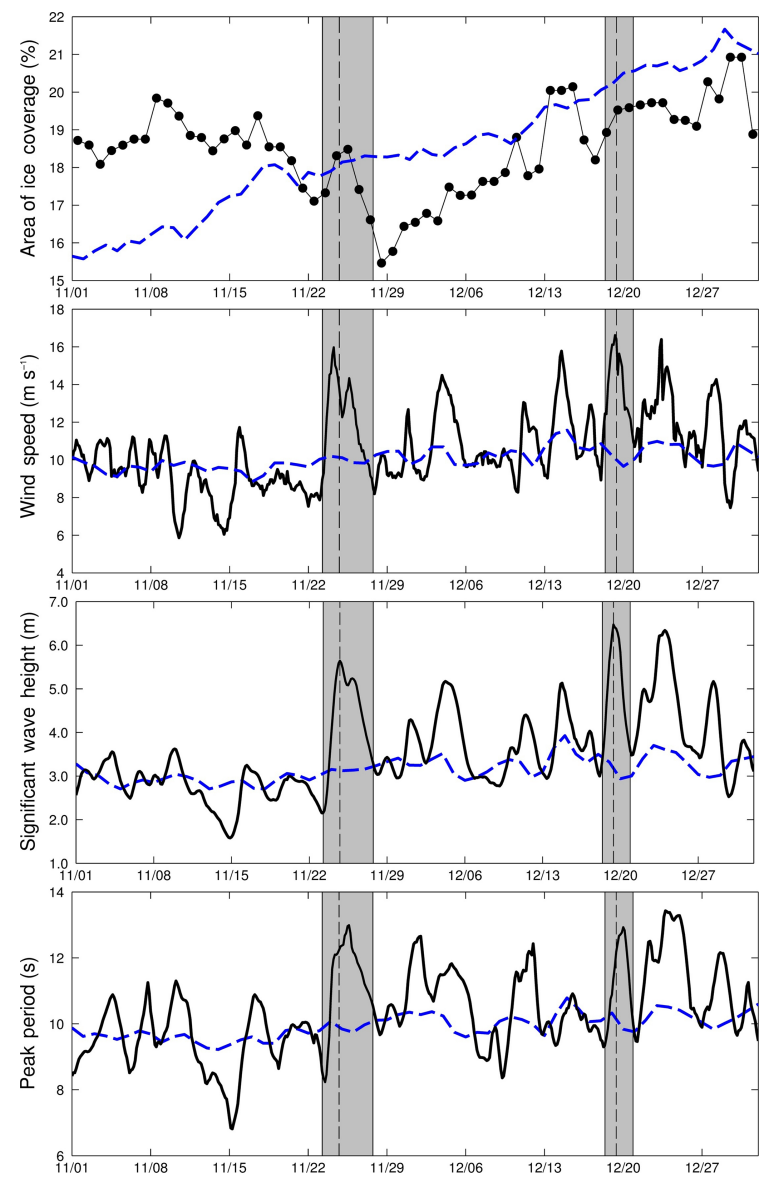

Figure 10. Area-averaged ice coverage, wind speed, significant wave height, and peak period in the Greenland Sea for NovemberDecember 1992 (solid line). The dashed line is the daily average from 1992 to 2014.

Nordic Sea has less statistically significant points, suggesting changes in the local winds are causing the trends. The bottom-center panel displays the wind-sea steepness $\left(\mathrm{ST}_{\mathrm{w}}\right)$ (ratio of wind-sea wave height versus wavelength). The wave steepness reduces, illustrating that the wavelengths become longer than the wave heights are becoming taller. However, the trends in swell steepness have the same pattern as $H_{\mathrm{s}}$, meaning the swell wavelengths are changing proportionally to the heights (not shown). Finally, the WA is increasing across the entire domain, albeit some decreasing regions exist near the MIZ in the Beaufort Sea, Greenland Sea, and Baffin Bay. Consequently the wave phase speeds are increasing faster than the driving wind fields and swells are becoming more prevalent.

Trends often contain a component of natural variability which may lead to opposite trends in the future. The North Atlantic Oscillation (NAO) has a strong influence in the Nordic Greenland Sea shown by Semedo et al. (2014) and in the Beaufort-Chukchi seas, the Pacific Decadal Oscillation (PDO) influences the ice and wind dynamics (Frey et al.,
2015). Table 1 presents correlation coefficients between areaaveraged monthly time series of sea ice, $\mathrm{U} 10$, and $H_{\mathrm{s}}$ and the NAO and PDO indices (see Appendix D for spatial distribution). The statistically significant relationship in the wind and wave fields with the NAO is moderate in the Nordic Greenland and Barents seas. In these seas, a positive NAO phase equates to increased sea states while negative phases have reduced sea states. The NAO was positive in the beginning of the time period (1992-1998) and negative towards the end of the hindcast (2006-2012). This creates a negative trend and its positive relationship with the sea states and wind suggests the NAO is causing the negative wind and wave trends observed in Nordic Greenland and Barents seas. Table 1 shows that the PDO is weakly related in the Beaufort-Chukchi seas. Higher values are attained by correlating the time series for each point (see Appendix D).

Figure 9 summarizes the regional trends through Sen's slope of the NAO, PDO, ice-free area, U10, and $H_{\mathrm{s}}$. The NAO and PDO have statistically significant decreasing trends. The NAO is influencing the decreasing trend in the Nordic, Greenland, and Barents seas seen in Figs. 7 and 8. The most prominent feature is the increase in ocean area or reduction of ice cover. The $H_{\mathrm{s}}$ trends are not homogeneous showing the regional variability. The largest trends in oceanarea and $H_{\mathrm{s}}$ occur in the Laptev and East Siberia seas. All seas except the Baffin Bay have stronger trends in the average $H_{\mathrm{s}}$ compared to the 95 th percentile, suggesting nonuniform changes in the statistical distributions. When the average trend is higher than the 95th percentile it means that moderate events occur more frequently compared to an intensification of strong events. In the Baffin Bay the trends in the 95th percentile are larger than the average, suggesting the intensification of strong events. The wave trends computed for the co-located altimeters and model show the model underestimates (consistent with Fig. 7). The $H_{\mathrm{s}}$ average and 95th percentile have larger trends than the results in the global ocean, which were typically less than $1 \%$ (Young et al., 2011). The trivial U10 trends illustrate that the increased sea states are due to the reduction of ice cover in agreement with Wang et al. (2015).

\section{Wave impact on the sea ice}

Thus far, we have seen that decreasing the sea ice drastically affects the wave climate and amplifies sea states. The waves also impact sea ice but their influence remains unknown due to lack of observations and understanding of the wave-ice processes (Squire, 2007; Wadhams and Doble, 2009; Li et al., 2015). Large storms affect the Arctic as demonstrated by Simmonds and Rudeva (2012) and Zhang et al. (2013); however, the impacts from waves are less evident. Therefore we qualitatively describe the wave influence on the sea ice with selected events from the Nordic Greenland and BeaufortChukchi seas. We chose these regions because their wave 

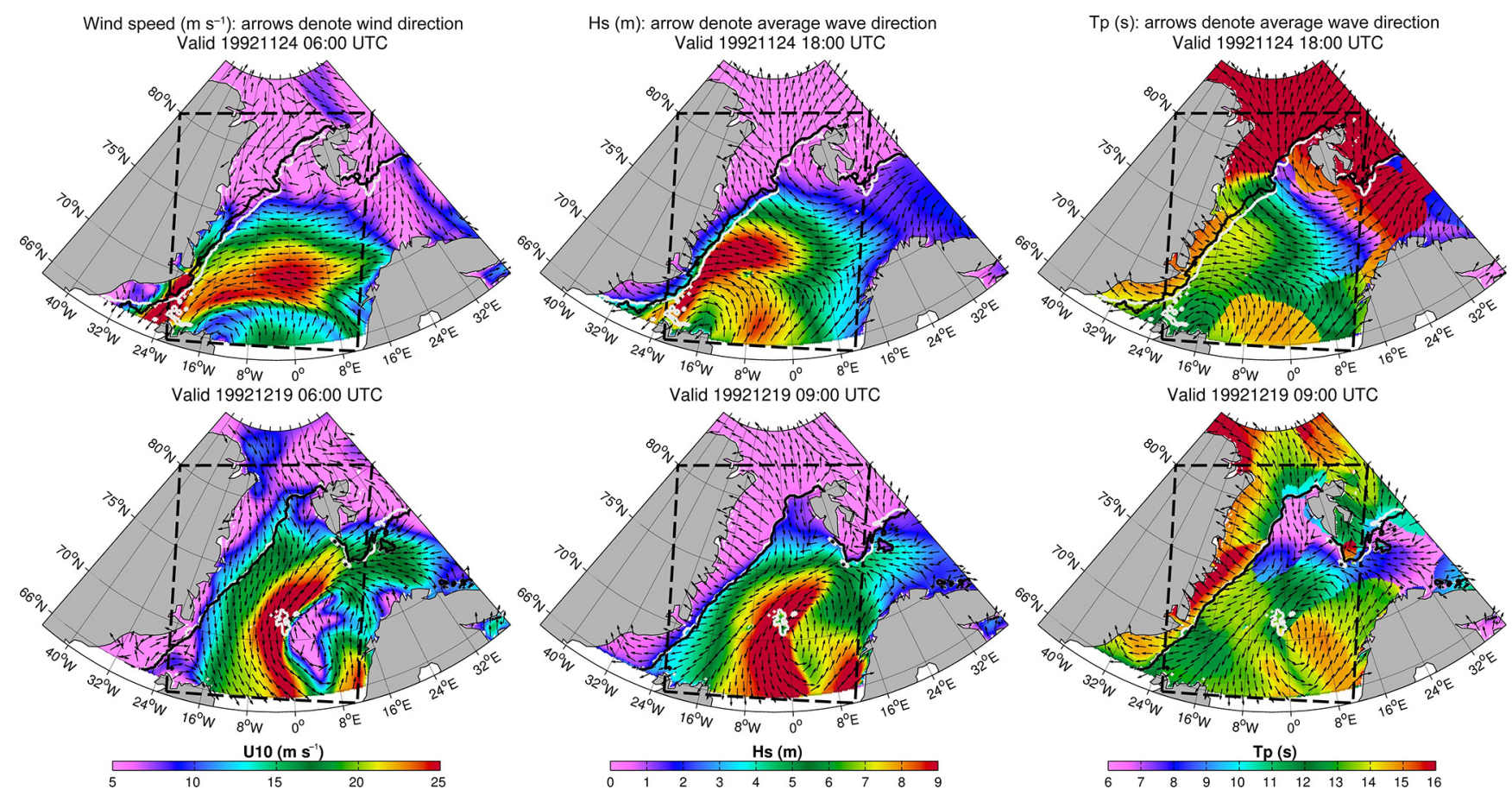

Figure 11. Wind speeds, significant wave heights, and peak periods for events in November and December 1992. The arrows denote the wind direction or average wave direction. The contour lines represent the $15 \%$ ice concentration before (white) and after (black) the event.

environments are different: the Nordic Greenland seas are influenced by swells from the North Atlantic and the BeaufortChukchi seas is characterized by an equal mix of wind waves and swells coupled with an extreme change in seasonal ice coverage.

Figure 10 shows the Nordic Greenland Sea area-averaged ice and sea state conditions for 2 months in 1992. The 23year climate average (dashed line) shows the ice cover climatology increases $6 \%$ from November through December. The first event, on 23-29 November, indicates a decrease in ice cover by $-3 \%$ or $\sim 60000 \mathrm{~km}^{2}$. This event coincides with $H_{\mathrm{s}}$, peak periods, and wind speeds exceeding $5 \mathrm{~m}, 12 \mathrm{~s}$, and $14 \mathrm{~m} \mathrm{~s}^{-1}$, respectively. The second event in December has larger wave heights $(>6 \mathrm{~m})$, but the ice cover remains the same.

We compare and contrast these two events in Fig. 11 by showing snapshots of the wind speed, wave height, and wave period. During the November event, the ice edge changes considerably before and after the event (white and black lines). The wind field rotation is cyclonic and centered near Iceland $\left(14^{\circ} \mathrm{W}, 66^{\circ} \mathrm{N}\right)$. An anti-cyclonic pattern $\left(6^{\circ} \mathrm{E}\right.$, $78^{\circ} \mathrm{N}$ ) adds to the effective fetch. U10 exceeds $20 \mathrm{~m} \mathrm{~s}^{-1}$ and $H_{\mathrm{s}}$ exceeds $9 \mathrm{~m}$ close proximity to the ice with wave periods ranging from 12 to $15 \mathrm{~s}$. Further into the sea ice only the largest wave periods remain due to the attenuation of the short wavelengths. The wind and wave directions are largely perpendicular to the Greenland ice edge. The largest sea ice changes are located from 70 to $77^{\circ} \mathrm{N}$, corresponding to the maximum wave energy and wind speed. The bottom panels of Fig. 11 show the December storm is located further $\left(7^{\circ} \mathrm{E}\right.$, $71^{\circ} \mathrm{N}$ ) from the Greenland ice edge. This leads to a reduction of wind speeds $\left(<18 \mathrm{~m} \mathrm{~s}^{-1}\right)$, wave heights $(3 \mathrm{~m})$, and periods $(12 \mathrm{~s})$ close proximity to the ice edge. The minimal change in ice coverage is related to the reduced wind and wave energy entering the ice. We do not consider the ice thickness in our analysis; therefore it is not apparent how much ice volume is lost by either event.

Figure 12 shows the ice cover and sea state conditions in the Beaufort-Chukchi seas in September and October 2006. During this time of year the ice increases and advances southward. Both 13-16 September and 9-11 October have changes in sea ice coverage. In the first event the ice coverage reduces by $12 \%$, equating to $226000 \mathrm{~km}^{2}$, while in the second event the decrease of $6 \%$ equates to $113000 \mathrm{~km}^{2}$. The second event has $H_{\mathrm{S}}$ of $6 \mathrm{~m}$, which is well above the climatology average of $2 \mathrm{~m}$. The sea state is much weaker in the first event than in the second.

Figure 13 illustrates the corresponding sea state conditions. The September case has winds predominately from the South directed into sea ice from the Bering Strait. The wind speeds are strengthened by the pressure gradient force created by the tall mountain ranges in Alaska and Russia which exceed $2 \mathrm{~km}$ in height. The wind speeds, wave heights, and periods reach $18 \mathrm{~m} \mathrm{~s}^{-1}, 4.5 \mathrm{~m}$, and $9 \mathrm{~s}$ offshore of the ice. The area of polynya located near $\left(158^{\circ} \mathrm{W}, 77^{\circ} \mathrm{N}\right)$ does not change much and is translated towards the Pole. There are 

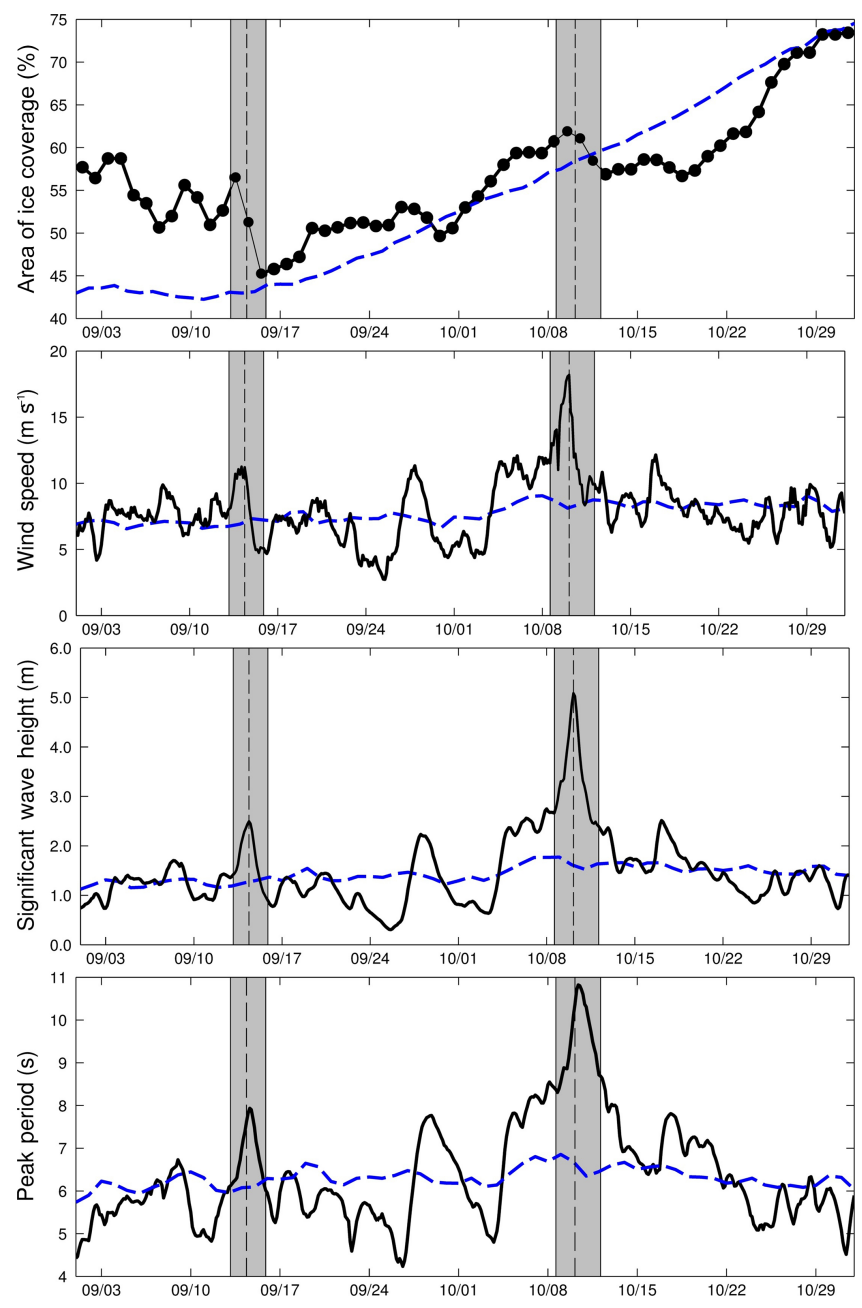

Figure 12. Area-averaged ice coverage, wind speed, significant wave height, and peak period in the Beaufort-Chukchi seas for September-October 2006 (solid line). The dashed line is the daily average from 1992 to 2014.

significant changes to the ice edge and a large indentation coincides with the maximum wind and wave energy. Besides this isolated section, the rest of the Beaufort ice edge remains the same. The October event has large wind speeds, wave heights, and wave periods exceeding $24 \mathrm{~m} \mathrm{~s}^{-1}, 8 \mathrm{~m}$, and $13 \mathrm{~s}$. In fact, this is the strongest event from 23-year hindcast and $H_{\mathrm{s}}$. The wave heights exceed $8 \mathrm{~m}$ and are well above the 99th percentile of Fig. 6. The wind field has a cyclonic pattern confirmed to be a polar low centered in the Chukchi Sea $\left(162^{\circ} \mathrm{W}, 62^{\circ} \mathrm{N}\right)$ and an anti-cyclonic pattern (high-pressure system) centered over the sea ice $\left(132^{\circ} \mathrm{W}, 80^{\circ} \mathrm{N}\right)$. The positions of these systems create an extended fetch for wave development because the eastern winds are directed parallel to the sea ice. Ekman transport could be moving warmer water towards the sea ice. In addition, the extreme wind and waves enhance mixing, which could transport warm waters to the ice. As time evolves the systems move further north creating a larger southerly component in the eastern portion of the domain where significant impacts occur in the sea ice coverage.

These examples suggest a relationship between the evolution of sea ice and the amount of wind and wave energy directed into the MIZ. The incident angle of the winds and waves to the sea ice plays a critical role on sea ice, so the location of the storm relative to the ice edge is important. Other physical processes that influence sea ice include temperature change, ocean circulation, and transport due to wind (Frey et al., 2015). These examples illustrate how waves impact the sea ice and should be considered as a potential sea ice driver.

\section{Discussion}

Coupling between waves and sea ice is complex (e.g., Squire et al., 1995; Squire, 2007). While the inclusion of the waveice dissipation term is a step to incorporate improved waveice processes within the wave model, redistribution of the wave energy through scattering must also be considered (Squire et al., 1995). Furthermore, wind-wave generation in partially ice-covered waters is expected to be more complex than as parameterized in present wave models ( $\mathrm{Li}$ et al., 2015). Despite these missing physical processes, the 23 -year hindcast presented here performs well offshore of the sea ice as demonstrated by the $H_{\mathrm{s}}$ comparison to the altimeters.

The wave conditions in the Arctic are governed by the sea ice and winds and we observe two distinct regions: (1) semienclosed basins and (2) region exposed to the North Atlantic. The semi-enclosed and isolated seas of Kara, Laptev, East Siberia, Beaufort-Chukchi, and Baffin Bay makes them event driven and explains why they have an equal mix of wind seas and swells. Here the sea state magnitudes are comparable to those in the Gulf of Mexico (Stopa et al., 2013a). The Atlantic side of basin has the most active sea states because it is exposed to the Atlantic and is mostly ice-free year round. Here the wave seasons follow the winds and behave like a sinusoid. Extreme events in these seas are limited by the basin's size and the wave directions are parallel to the ice edge. Therefore, to a leading order the wave behavior is linked to the geography and ice conditions which control the effective fetch for wave development (Thomson and Rogers, 2014; Smith and Thomson, 2016).

The wave field is very sensitive to concurrent ice-free conditions and strong wind speeds, which are more prevalent in the fall (Fig. 4). This explains why we observe a skewed seasonal cycle that has maximum wave heights occurring in October and November for the semi-enclosed basins. Figure 2 shows the trend of minimum ice cover from SSM/I occurs later in September. In addition the sea ice is becoming icefree for longer durations. The reduction of sea ice cover in the last 23 years enabled wave heights to increase as verified by our hindcast and altimeter data sets, which agree 

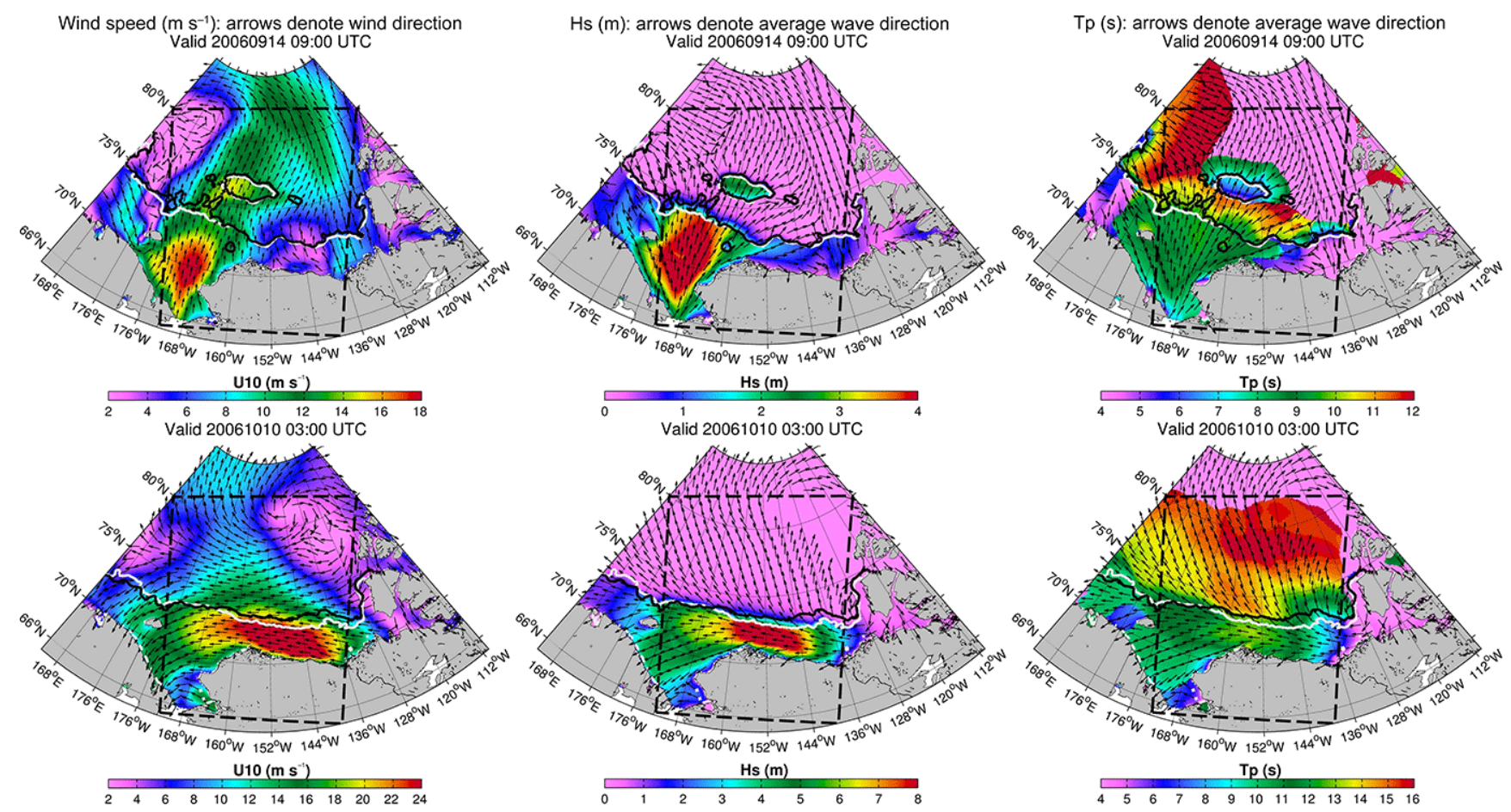

Figure 13. Wind speeds, significant wave heights, and peak periods for events in September and October 2006. The arrows denote the wind direction or average wave direction. The contour lines represent the $15 \%$ ice concentration before (white) and after (black) the event.

with prior studies (Wang et al., 2015; Francis et al., 2011). If these trends continue the sea state will continue to increase as well. The Arctic sea ice in the semi-enclosed basins are more sensitive to the wave conditions in the fall compared to the other seasons due to concurrent increasing winds and partially open seas this time of year. Therefore we expect the Arctic to be very sensitive to changes in sea ice, winds, and waves in the fall compared to any other time period. This has led Thomson and Rogers (2014) and Thomson et al. (2016) to suggest a positive feedback mechanism linking enhanced wave heights to the larger ocean expanses which cause more ice breakup. However, this process is convoluted by the fact that the wave steepness is lessened, which reduces the effectiveness of the ice breakup by waves.

The wave response to the changing sea ice through the 21 st century is complex, with a mix of influences from wind, sea ice, and climate variability (Khon et al., 2014). In the majority of the Arctic, wave heights are increasing. The only region with decreasing wave heights is in the Nordic Greenland Sea. In our hindcast time period of 1992-2014, the natural variability of the climate through the NAO and PDO impacts the Arctic sea state. The negative trends observed in the sea state are expected to be caused by the NAO. The PDO influences the Barents and Kara seas and the monthly correlation coefficients closely aligns with the maximum ice loss. In the Beaufort-Chukchi seas the PDO plays a minor role in the wind and wave fields, but this should be monitored when the PDO transitions into a positive phase.
The impact of waves on the sea ice is difficult to determine without detailed knowledge of wave-ice interaction. The evolution of the ice edge seems to respond to the amount of wind and wave energy near the ice pack as demonstrated in the Nordic Greenland and Beaufort-Chukchi seas. The orientation of the driving wind fields and their incident angles relative to the sea edge is important for sea ice evolution (Kohout et al., 2014). For example, the Great Arctic Cyclone of 2012 persisted for 13 days and had a significant impact on the sea ice (Simmonds and Rudeva, 2012; Zhang et al., 2013). However, this storm did not produce substantial waves according to our hindcast, due to its passage over ice-covered regions. If the location of the event had been positioned more appropriately for wave development, then this long-lived event could have produced large waves. The time duration of the wind and wave influence is less evident in sea ice evolution. For example, the percentage of ice cover remains relatively constant for a 10-day period after the October 2006 event in the Beaufort-Chukchi seas. The sea ice variability is influenced by many drivers including atmospheric motion, oceanic motion, air-sea temperatures, and changes in cloud cover (Perovich, 2011); waves should also be added to the list. 


\section{Conclusions}

Extending previous studies of Francis et al. (2011), Wang et al. (2015), and Semedo et al. (2014) to the Arctic, we produced a 23-year wave hindcast from 1992 through 2014 using CFSR winds and ice concentrations from SSM/I. The combined use of models and satellite observations proves to be a robust way of monitoring and describing the climate. As the Arctic continues to change, the results presented here can be used as a basis for future climate studies or projections such as those presented by Khon et al. (2014) or Dobrynin et al. (2012). Our observed changes in the wave field are expected to be influencing the coastlines, ecosystem, and sea ice melt (e.g., Overeem et al., 2011; Tremblay et al., 2008; Popova et al., 2010; Davis et al., 2016). Since the Arctic is semi-enclosed, the sea states are event driven and this creates distinct features in the wind seas and swells. If the open ocean persists later into the fall, then the sensitivity of the Arctic sea state and ice conditions will increase since this season has stronger wind speeds. The reduction in ice extent enhanced sea states with taller wave heights, longer wavelengths, and more persistent swells. While it is not evident how important wave-ice processes are within the Earth system, the increasing sea states in the Arctic do have critical and direct implications on the environment.

\section{Data availability}

The CFSR and ERAI reanalysis data are publicly available from rda.ucar.edu and the IFREMER/CERSAT sea ice concentration is available from ftp.ifremer.fr/ifremer/cersat/. The altimeter data are available from ftp://ftp.ifremer.fr/ ifremer/cersat/products/swath/altimeters/waves/. Wave hindcast data will be made available at ftp://ftp.ifremer.fr/ifremer/ ww3/HINDCAST/ (Stopa, 2015). 
Appendix A: The ECMWF-Interim reanalysis and the NCEP Climate Forecast System Reanalysis arctic intercomparison 2010-2014

Before the 23-year hindcast was implemented, we intercompared two 5-year hindcasts using CFSR and ERAI winds to establish the better-suited wave forcing. Measured wave data are essential for validation and we use buoy and altimeter observations. Only a limited number of buoys are available from the National Data Buoy Network (NDBC) in the Chukchi Sea and their locations are shown in Fig. 1. Only select years and $H_{\mathrm{s}}$ measurements are available from July through October (2012-2014) in depths less than 50 m. Standard error metrics are used to assess the models including the normalized bias (NBIAS), RMSE, correlation coefficient $(R)$, scatter index (SI), and normalized standard deviation (NSTD), where $x$ represents the observation, $y$ represents the model, and $n$ is the number of data pairs:

$$
\begin{aligned}
& \text { NBIAS }=\left[(\bar{y}-\bar{x}) /\left(\frac{1}{n} \sum_{i=1}^{n} x_{i}^{2}\right)\right] \times 100 \\
& \text { RMSE }=\sqrt{\frac{1}{n} \sum_{i=1}^{n}\left(y_{i}-x_{i}\right)^{2}}
\end{aligned}
$$

$$
\begin{aligned}
R= & \sum_{i=1}^{n}\left(y_{i}-\bar{y}\right)\left(x_{i}-\bar{x}\right) /\left[\sqrt{\frac{1}{n} \sum_{i=1}^{n}\left(y_{i}-\bar{y}\right)^{2}}\right. \\
& \left.\sqrt{\frac{1}{n} \sum_{i=1}^{n}\left(x_{i}-\bar{x}\right)^{2}}\right]
\end{aligned}
$$

$\mathrm{SI}=\left[\sqrt{\frac{1}{n} \sum_{i=1}^{n}\left[\left(y_{i}-\bar{y}\right)-\left(x_{i}-\bar{x}\right)\right]^{2}} / \bar{x}\right] \times 100$

$\mathrm{NSTD}=\left[\sqrt{\frac{1}{n} \sum_{i=1}^{n}\left(y_{i}-\bar{y}\right)} / \sqrt{\frac{1}{n} \sum_{i=1}^{n}\left(x_{i}-\bar{x}\right)} /-1\right] \times 100$.

Table A1 displays error $H_{\mathrm{s}}$ metric with the NDBC buoys. The CFSR hindcast overestimates the $H_{\mathrm{S}}$ by at least $5 \%$ at all locations while the ERAI hindcast underestimates by $3 \%$ (except WMO48213). The RMSEs are commonly $0.25 \mathrm{~m}$, with the ERAI hindcast always having a better agreement. The scatter indices and correlation coefficients for the ERAI and CFSR wave hindcasts are similar at each buoy. The NSTD shows the CFSR hindcast has more variability than the observations while the ERAI hindcast is smoother. In general both hindcasts are comparable but the CFSR hindcast has a positive bias while the ERAI hindcast has a negative bias.
Figure A1 displays two example time series from September 2013 and 2014 at buoys WMO 48213 and 48214 located in the Chukchi Sea. The first example in 2013 shows both models perform reasonably well. The time series of the ERAI hindcast is smoother and has a correlation coefficient of 0.89 . The CFSR hindcast is seen to overestimate the events on 13 and 26-28 September with differences larger than $0.5 \mathrm{~m}$. For these events the ERAI hindcast follows the same pattern, suggesting a systematic error in the forcing wind field or wave physics that are unresolved. The hindcast residuals (CFSR-buoy and ERAI-buoy hindcasts) are moderately correlated with coefficients of 0.75 , showing that the forcing wind fields are similar. In September 2014, both ERAI and CFSR hindcasts are highly correlated to the buoy time series and their residuals are only weakly correlated with a coefficient of 0.37 . The CFSR hindcast has a consistent positive bias throughout the month, while the ERAI hindcast commonly has errors less than $25 \mathrm{~cm}$. Notice that the peak intensity of wave events is underestimated by the ERAI hindcast.

Figure A2 summarizes the $H_{\mathrm{s}}$ comparison from the altimeter and model co-locations using the 5 -year period. The scatter plots from all 2 million data pairs is presented in the top panels. Both data sets are highly correlated with similar SIs of $19 \%$ and have RMSEs of $\sim 0.4 \mathrm{~m}$. The smooth nature of the ERAI hindcast creates the negative NSTD of $10 \%$ while the CFSR hindcast is nearly 0 . The largest differences between the hindcasts are in the upper wave heights and the bottom panels highlight the differences. Both data sets have similar correlation coefficients of 0.78 and scatter indices of $13 \%$. The CFSR hindcast has more variability than the observed data, creating a NSTD of $20 \%$ while the ERAI hindcast matches the variability of the observations much better. From this depiction it is clear that the ERAI hindcast underestimates the largest wave heights. For example, the 99th $H_{\mathrm{s}}$ percentile has an average bias of $-1.5 \mathrm{~m}$ while it is $-0.1 \mathrm{~m}$ for the CFSR hindcast. These large sea states are important to resolve in practical planning and engineering applications. Therefore caution should be applied when using extreme waves from a hindcast that uses ERAI winds as forcing. In our implementation of the ERAI hindcast, $\beta_{\max }$ described in Ardhuin et al. (2010) is set to 1.45 and possibly a better match could be achieved by increasing this value.

Figure A3 compares the $H_{\mathrm{S}}$ medians as well as the 99th percentiles. The top left and center panels display the percentiles from the CFSR hindcast and the differences between the CFSR and ERAI hindcasts are given in the bottom panels. The medians are clearly different and the ERAI hindcast is less than the CFSR hindcast by 0.1 to $0.4 \mathrm{~m}$ throughout the Arctic. The wave heights from the 99th percentile have large differences of $2 \mathrm{~m}$ in the area east of Greenland. Otherwise the waves in the ERAI hindcast are $0.5 \mathrm{~m}$ less than the CFSR hindcast across the semi-enclosed seas. The top right panel shows that the data sets are highly correlated with coefficients larger than 0.95 and exceed 0.98. The MannWhitney test reveals that the medians come from different 
Table A1. $H_{\mathrm{S}}$ error metrics for select years in the Beaufort-Chukchi seas using CFSR and ERAI in parentheses.

\begin{tabular}{cccccccrr}
\hline Buoy ID & Depth $(\mathrm{m})$ & Years valid (YY) & $\mathrm{N}$ & NBIAS $(\%)$ & RMSE $(\mathrm{m})$ & SI $(\%)$ & $R$ & NSTD $(\%)$ \\
\hline All & - & $12,13,14$ & 7574 & $+8.44(-3.14)$ & $0.29(0.25)$ & $20.71(20.05)$ & $0.94(0.94)$ & $+1.42(-5.55)$ \\
WMO48213 & 50.01 & 13 & 1700 & $+11.40(+1.36)$ & $0.31(0.28)$ & $25.99(26.39)$ & $0.91(0.91)$ & $+6.22(+6.97)$ \\
WMO48214 & 36.13 & $12,13,14$ & 3956 & $+7.79(-3.52)$ & $0.27(0.24)$ & $17.55(16.43)$ & $0.94(0.95)$ & $+0.79(-9.06)$ \\
WMO48213 & 41.16 & 12 & 568 & $+5.66(-3.67)$ & $0.28(0.23)$ & $15.68(13.57)$ & $0.95(0.95)$ & $-11.66(-10.30)$ \\
WMO48211 & 32.52 & 13 & 1350 & $+9.95(-8.22)$ & $0.30(0.26)$ & $30.72(27.53)$ & $0.87(0.88)$ & $+10.61(-13.24)$ \\
\hline
\end{tabular}
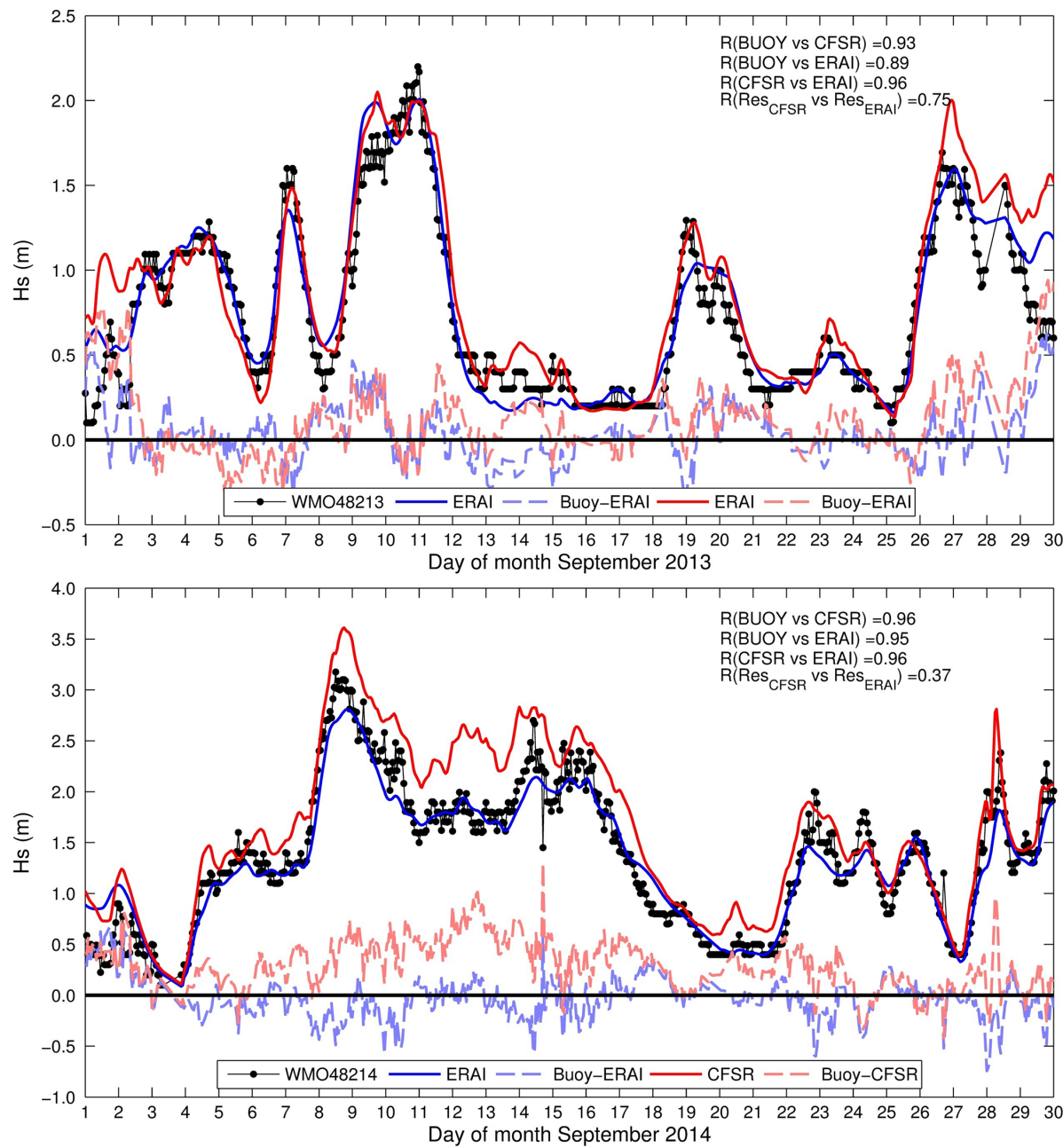

Figure A1. Buoy $H_{\mathrm{S}}$ time series for September 2013 (top) and 2014 (bottom). The solid red and blue lines denotes ERAI and CFSR. The dashed lines represent the residual (buoy model). 

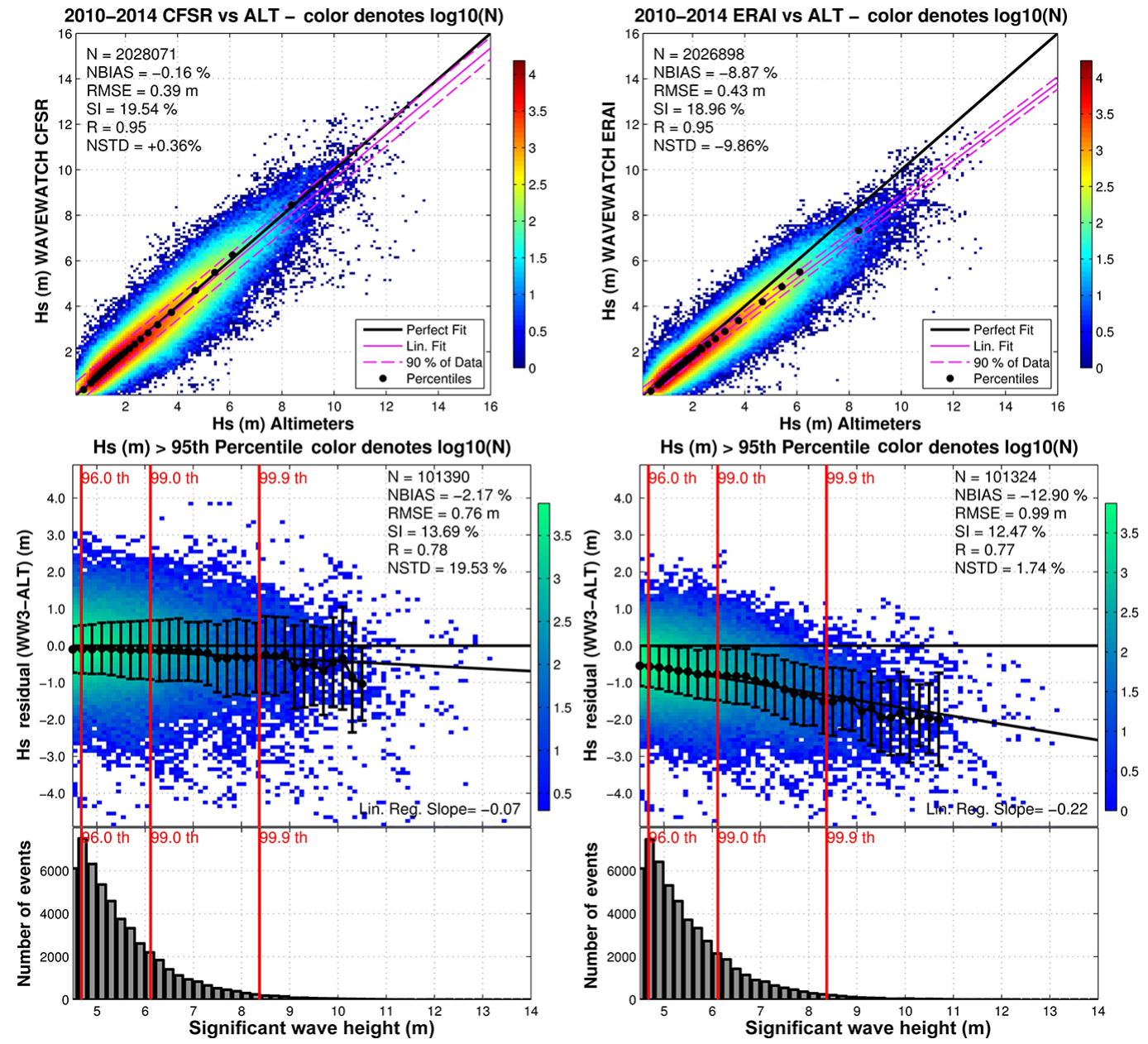

Figure A2. Significant wave height comparison from CFSR (left) and ERAI (right) versus co-located data from altimeters. The error dispersion of the models is presented in a scatter plot with the density given in a logarithmic scale (top panels). The upper percentiles are highlighted to show the differences (bottom panels).

statistical distributions at the $99.9 \%$ confidence limit for the entire domain. Figure A4 shows the probability distributions of the hindcasts, buoys, and altimeters. The CFSR hindcast matches the wave heights larger than $2.5 \mathrm{~m}$ well, while the ERAI hindcast consistently underestimates. When the $H_{\mathrm{S}}$ is less than $2.5 \mathrm{~m}$ the CFSR hindcast overestimates. The ERAI hindcast tends to favor the small wave heights. The buoy comparison in the right panel shows similar features. Here the CFSR hindcast overestimates average wave heights of 1$2.5 \mathrm{~m}$, which agrees with the examples shown in Fig. A1. Therefore we can conclude that the extreme waves and the average conditions are different in the two hindcasts.

In conclusion, both data sets perform reasonably well and their results agree with errors found in the global ocean (Stopa and Cheung, 2014). The CFSR wave hindcast consistently predicts higher wave heights for average sea states and matches the upper percentiles much better. The upper wave heights in the ERAI hindcast diverge from the observations and the 99th percentile has an average bias of $1.5 \mathrm{~m}$. In summary, the ERAI hindcast is better suited to describe the average conditions and the $6 \mathrm{~h}$ increment and spatial resolution of 0.7 limits its ability to resolve the peak intensity of the storms. Due to the importance of resolve the upper wave heights we choose the CFSR winds to hindcast the entire period from 1992 to 2014. 


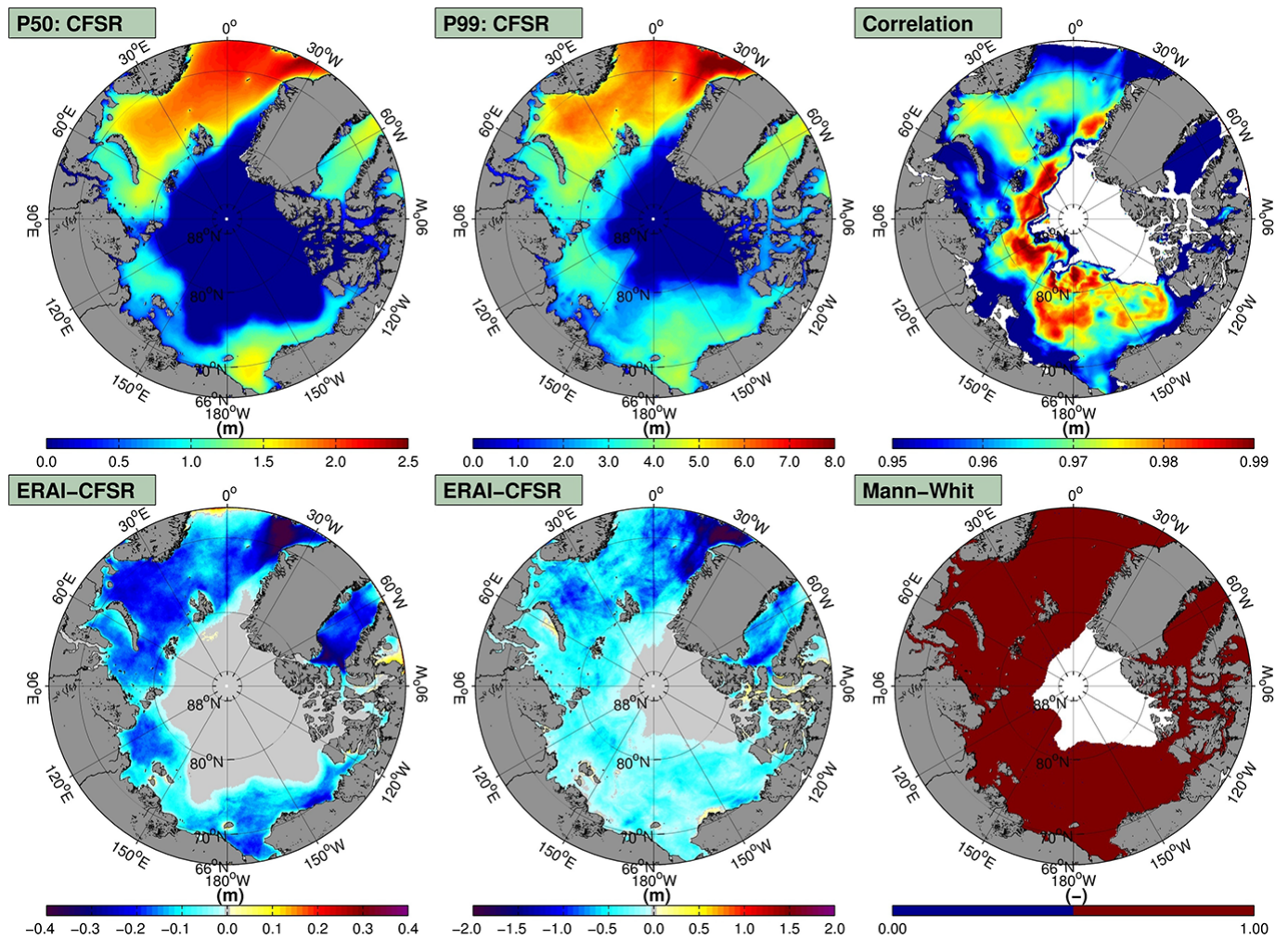

Figure A3. The 50th and 99th $H_{\mathrm{S}}$ CFSR percentiles (2010-2014) (top left and middle panels). ERAI-CFSR 50th and 99th percentiles are given in the bottom left and middle panels. The top right panel shows the correlation coefficients between ERAI and CFSR for a monthly averaged time series between CFSR and ERAI. The Mann-Whitney test is presented in the bottom right panel at the $99.9 \%$ confidence limit.
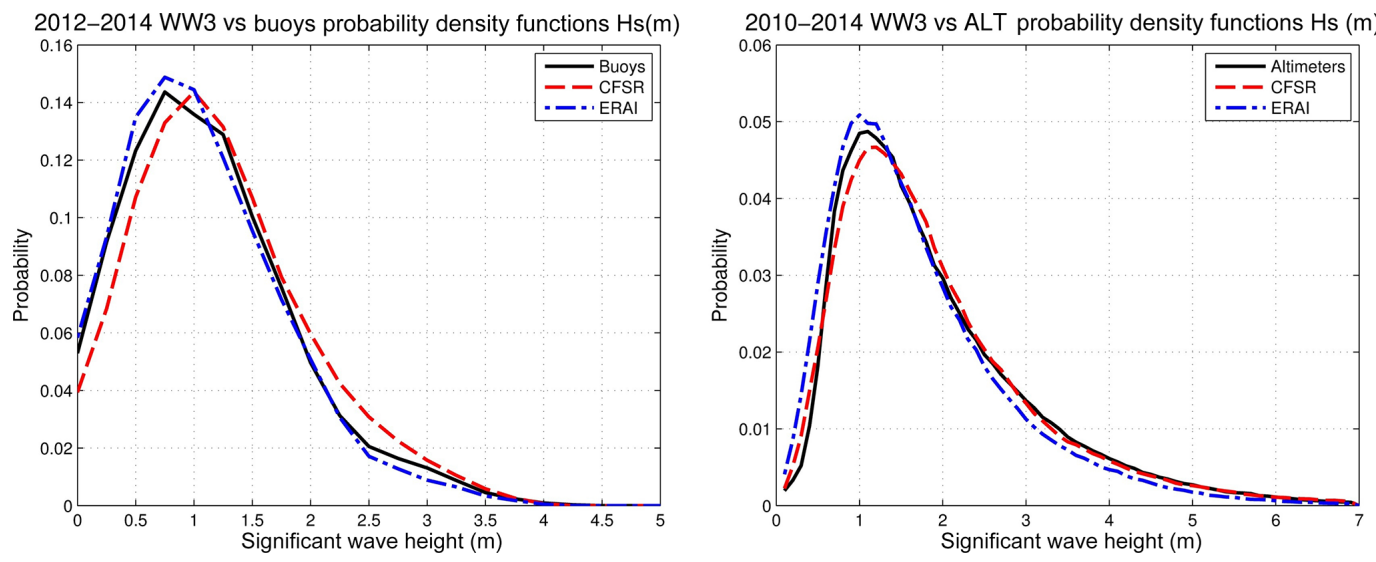

Figure A4. $H_{\mathrm{S}}$ probability distributions for CFSR and ERAI versus the buoys (left) and altimeters (right). 


\section{Appendix B: Theoretical formulation of friction under ice plates}

\section{B1 Extension of the theory by Liu et al.}

The representation of dissipative source terms in spectral wave models can generally be cast in a quasi-linear form (Komen et al., 1994):

$S(f, \theta)=\beta \sigma E(f, \theta)$,

where $E(f, \theta)$ is the frequency-direction spectrum of the surface elevation, $\sigma=2 \pi f$, and $\beta$ is a nondimensional dissipation coefficient that is negative when wave energy is actually dissipated. Previous treatments of the dissipation of wave energy due to friction below an ice layer have been confined to a laminar viscous boundary layer and presented by (Liu and Mollo-Christensen, 1988):

$\beta_{v}=-k \sqrt{v \sigma / 2} /(1+k M)$,

in which $k$ and $\sigma$ are the wave number and radian frequency, related by a dispersion relation that can be affected by the ice, and $M$ is the ice inertia effect related to the ice thickness multiplied by the ratio of ice to water density. In the present paper, because we focus on the dominant long-period waves for which the effect of the ice is less, we have used the icefree dispersion relation $\sigma^{2}=g k \tanh (k D)$ in which $D$ is the water depth and $g$ the acceleration of gravity. For these long waves, the factor $k M$ in Eq. (B2) can be neglected.

For practical applications, the obtained dissipation coefficient $\beta$ was then scaled up to fit observed wave attenuations by replacing the molecular viscosity at the freezing temperature of sea water, $v \simeq 1.83 \times 10^{-6} \mathrm{~m}^{2} \mathrm{~s}^{-1}$, by an eddy viscosity that was proposed to be as large as $0.3 \mathrm{~m}^{2} \mathrm{~s}^{-1}$ (Liu et al., 1991). Such a change in viscosity only makes sense when the flow is turbulent. Further, the functional form of the dissipation can be very different for laminar and turbulent frictions in an oscillatory flow near a boundary, as observed by (Jensen et al., 1989). In turbulent boundary layers, the energy dissipation coefficient typically grow with the wave amplitude, leading to a dependence of $\beta$ on the wave amplitude.

We thus revisit this question and propose a parameterization for the laminar to turbulent transition of the boundary layer below the ice. In turbulent conditions, an important parameter is the roughness length below the ice $z_{0}$. That roughness is unfortunately not well known, with only a few measurements of current boundary layers (e.g., McPhee and Smith, 1976). Because the roughness for the wave motion is probably different from the roughness for the currents, as it is well known for ocean bottom boundary layers (Grant and Madsen, 1979), we are left with the difficulty of defining the value of $z_{0}$. Given this roughness, the orbital velocity profile is expected to follow a Kelvin function (Grant and Madsen, 1979) with a dissipation source term that takes a form similar to that of bottom friction (e.g., Madsen et al.,

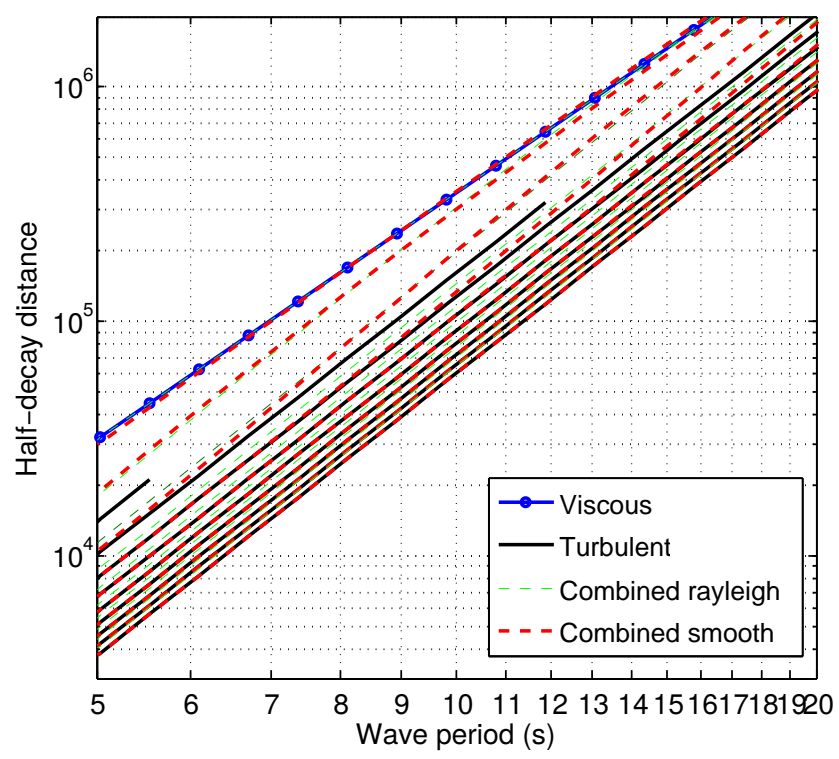

Figure B1. Half-decay distances as a function of the wave period $T$ and the significant wave height $H_{\mathrm{s}} . H_{\mathrm{S}}$ is varied from 0.5 (upper curves) to $5 \mathrm{~m}$ (lower curves). The combination of viscous and turbulent expressions is made using either a Rayleigh distribution of wave height and computing the dissipation for each wave height in the distribution or by a smooth linear combination of the viscous and turbulent terms adjusted to reproduce the Rayleigh result.

1990; Ardhuin et al., 2003) or swell dissipation by friction at the air-sea interface:

$\beta_{t}=-f_{e} u_{\mathrm{orb}} / g$

where the significant orbital amplitudes of the surface velocity is, for deep water waves,

$u_{\mathrm{orb}}=2 \sqrt{\int_{0}^{\infty}(2 \pi f)^{2} E(f) \mathrm{d} f}$.

$f_{e}$ is the same dissipation factor used for bottom friction, which is a function only of the ratio $a_{\text {orb }} / z_{0}$, where $a_{\text {orb }}$ is the significant orbital displacement at the sea surface, here for deep water waves $a_{\mathrm{orb}}=H_{\mathrm{s}} / 2$.

From bottom and air-sea boundary layer studies, the transition from laminar to turbulent is expected to occur at a threshold $R e_{\mathrm{c}}$ of the significant Reynolds number defined by

$R e=u_{\mathrm{orb}} u_{\mathrm{orb}} / \nu$.

We take the same critical value $R e_{\mathrm{c}}=1.5 \times 10^{5}$ found for the bottom boundary layer by (Jensen et al., 1989) and the airsea boundary layer by (Perignon et al., 2014). Because of the random nature of the waves, with Rayleigh-distributed wave heights, we expect a smooth transition of the average dissipation rate from viscous to turbulent. We found that the average dissipation caused by random wave heights that follow a 
Rayleigh distribution is well approximated by the following combined dissipation parameter

$\beta_{c}=(1-w) c_{v} \beta_{v}+w c_{t} \beta_{t}$,

in which $c_{v}$ and $c_{t}$ are empirical adjustment constants, expected to be close to 1 , and the weight $w$ transitions smoothly with the value of $R e$ over a range $\Delta_{R e}=200000$ :

$w=0.5\left[1+\tanh \left(\left(R e-R e_{\mathrm{c}}\right) / \Delta_{\mathrm{Re}}\right)\right]$.

Figure B shows the expected decay distance as a function of frequency, due to molecular viscosity (blue) or a turbulent boundary layer with a roughness $z_{0}=0.1 \mathrm{~mm}$, for significant wave heights ranging from 0.5 to $5 \mathrm{~m}$. In our applications we have chosen $z_{0}=1 \mathrm{~cm}$.

\section{B2 Empirical adjustment of the wave attenuation}

(Wadhams and Doble, 2009) have reported measurements of waves with periods larger than $20 \mathrm{~s}$ far into the ice pack (the periods reported in the paper were erroneously reduced by a factor 1.5; personal communication of M. Doble, 2015). An event with $20 \mathrm{~s}$ waves recorded $1400 \mathrm{~km}$ into the ice pack on 13 February 2007 had a maximum significant wave height of $3 \mathrm{~cm}$. For this small wave height the wave boundary layer is expected to be laminar. However, using the dissipation coefficient in Eq. (B6) produced maximum wave heights of $30 \mathrm{~cm}$. Changing only the coefficient $c_{v}$, it was necessary to increase it from 1 to 8 to obtain a reasonable agreement with the data. We have thus used that value to obtain reasonably small wave heights across the Arctic.

However, we note that $c_{v}=8$ tends to overestimate the dissipation in the Southern Ocean case discussed by (Ardhuin et al., 2015), for which $c_{v} \simeq 2$ is a better adjustment. Such differences could be partly caused by a more complex geometry of older ice in the Arctic, but a 4-fold increase of the area of the ice-water interface that could explain this difference is unlikely. It thus appears that the attenuation in the Arctic may be dominated by other processes than underice friction, especially when the ice is not broken. Different processes probably produce different distributions of wave heights in the ice. Given the weak energy level back-scattered in the open waters, the details of the wave attenuation process are not likely to affect much our analysis of wave climatology outside of the ice.

\section{Appendix C: Percentage of ice-free time}

In this study we present ice-free (when the concentration $>15 \%$ ) statistics. The statistics will vary based on how the ice conditions are included in the analysis and a number of methods are described by Tuomi et al. (2011). The different statistics can be related through the percentage of ice-free time presented in Fig. C1. The color bar is displayed in a logarithmic scale to highlight the details of the small ice percentages while including the regions rarely covered by ice. The Nordic Greenland Sea is ice free and the area closest to the North Pole is ice covered throughout the year. It is clear from this depiction that the largest changes occur in the Beaufort-Chukchi seas and are ice free less than $15 \%$ of the year above the latitude of $74^{\circ}$.

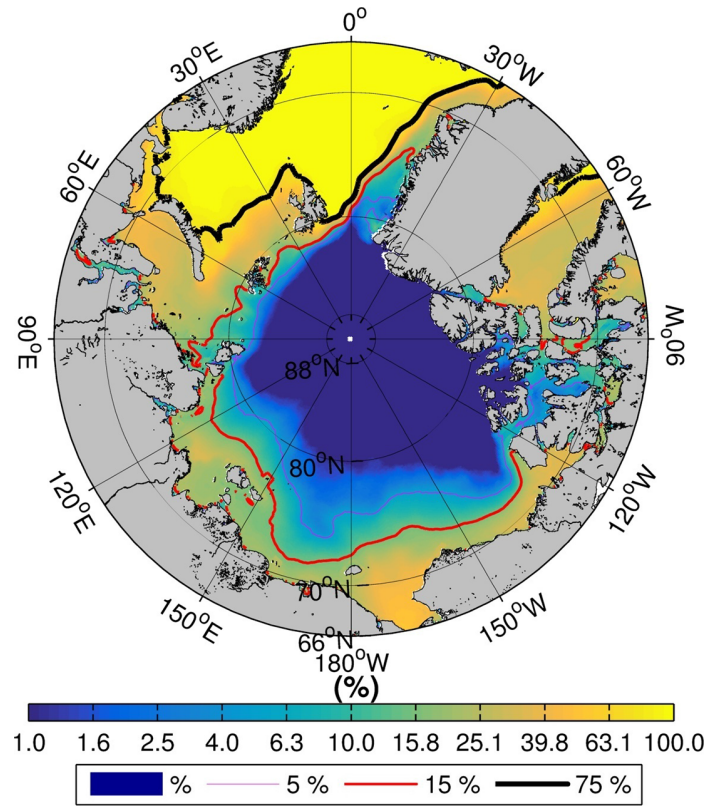

Figure C1. Percentage of ice-free time. Contours represent the 5th (thin purple line), 15th (medium red line), and 75th percentiles (thick black line). 


\section{Appendix D: Relationship with the North Atlantic Oscillation and Pacific Decadal Oscillation}

This study presents area-average correlation coefficients computed between monthly $H_{\mathrm{s}}$ and the NAO and PDO indices to quantify the strength of the relationship. These values can be less for individual time series of each point. Therefore we compute the correlation coefficients between the monthly average $H_{\mathrm{s}}$ and the climate indices for all grid points in Fig. D1. This is a more accurate portrait of the strength of the relationship and gives the full spatial distribution. It is clear the NAO has the strongest signature in the Nordic Greenland Sea and extends into the Barents Sea. The maximum correlation coefficient is 0.48 , which is larger than 0.37 in Table 1. Other regions have reduced correlation coefficients and are not spatially homogeneous. The PDO has been largely negative for the past decade and is creating the negative correlation coefficients across the Arctic. It is interesting to see that the largest relationship occurs in the Barents Sea $(R=-0.46)$, where the area-average results are much less $(R=0.1)$. Only a weak relationship exists in the BeaufortChukchi seas, contrary to what (Frey et al., 2015) showed for the ice and wind field.

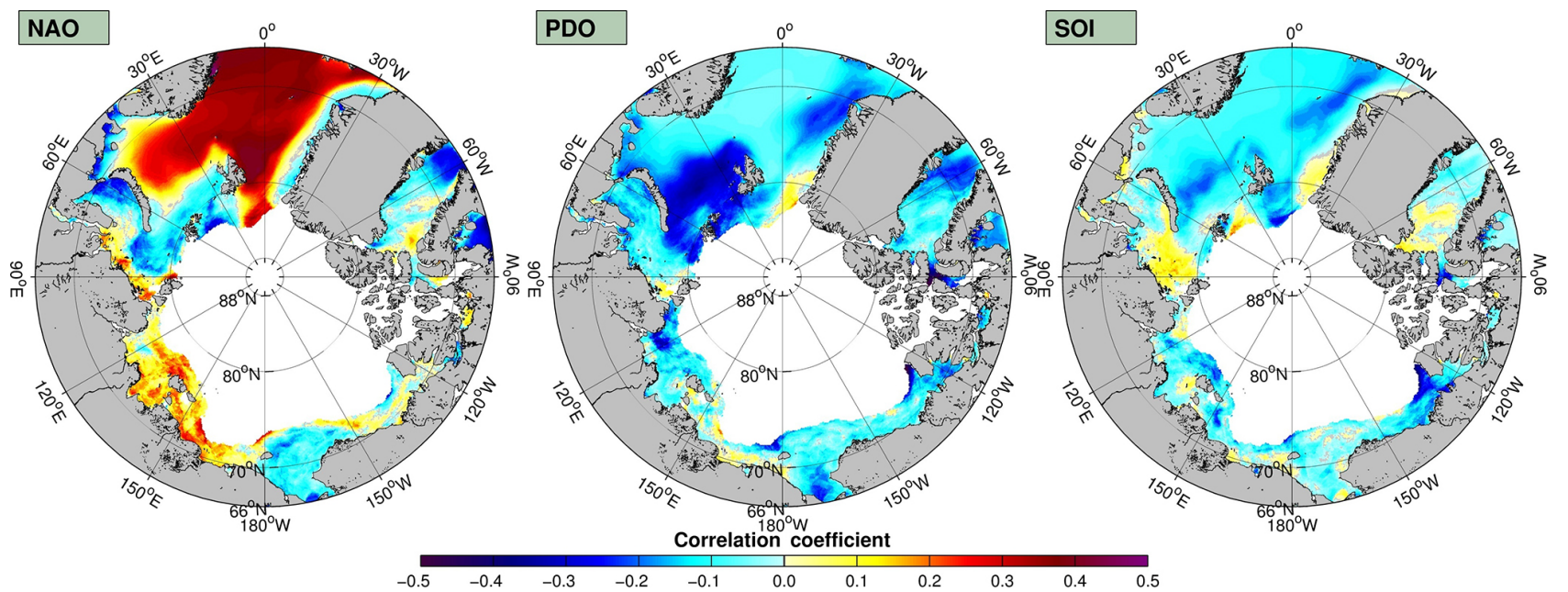

Figure D1. Correlation coefficients calculated from monthly time series of $H_{\mathrm{S}}$ of CFSR and the North Atlantic Oscillation (left) and Pacific Decadal Oscillation (right). 
Acknowledgements. This work was supported by LabexMER through grant ANR-10-LABX-19, École Centrale Nantes, and ONR grant number N0001416WX01117.

Edited by: R. Brown

Reviewed by: two anonymous referees

\section{References}

Anderson, J. D., Wu, C. H., and Schwab, D. J.: Wave climatology in the Apostle Islands, Lake Superior, J. Geophys. Res.-Oceans, 120, 4869-4890, doi:10.1002/2014jc010278, 2015.

Ardhuin, F., Herbers, T. H. C., Jessen, P. F., and OReilly, W. C.: Swell transformation across the continental shelf. part II: validation of a spectral energy balance equation, J. Phys. Oceanogr., 33, 1940-1953, 2003.

Ardhuin, F., Rogers, E., Babanin, A. V., Filipot, J.-F., Magne, R., Roland, A., van der Westhuysen, A., Queffeulou, P., Lefevre, J.-M., Aouf, L., and Collard, F.: Semiempirical Dissipation Source Functions for Ocean Waves. Part I: Definition, Calibration, and Validation, J. Phys. Oceanogr., 40, 1917-1941, doi:10.1175/2010jpo4324.1, 2010.

Ardhuin, F., Collard, F., Chapron, B., Girard-Ardhuin, F., Guitton, G., Mouche, A., and Stopa, J. E.: Estimates of ocean wave heights and attenuation in sea ice using the sar wave mode on sentinel1-A, Geophys. Res. Lett., 42, 2014GL062940, doi:10.1002/2014GL062940, 2015.

Cavalieri, D. J. and Parkinson, C. L.: Arctic sea ice variability and trends, 1979-2010, The Cryosphere, 6, 881-889, doi:10.5194/tc6-881-2012, 2012.

Chawla, A., Spindler, D. M., and Tolman, H. L.: Validation of a thirty year wave hindcast using the Climate Forecast System Reanalysis winds, Ocean Model., 70, 189-206, doi:10.1016/j.ocemod.2012.07.005, 2013.

Chen, G., Chapron, B., Ezraty, R., and Vandemark, D.: A Global View of Swell and Wind Sea Climate in the Ocean by Satellite Altimeter and Scatterometer, J. Atmos. Ocean. Technol., 19, 1849-1859, doi:10.1175/15200426(2002)019<1849:agvosa>2.0.co;2, 2002.

Comiso, J. C., Parkinson, C. L., Gersten, R., and Stock, L.: Accelerated decline in the Arctic sea ice cover, Geophys. Res. Lett., 35, L01703, doi:10.1029/2007g1031972, 2008.

Davis, P. E. D., Lique, C., Johnson, H. L., and Guthrie, J. D.: Competing Effects of Elevated Vertical Mixing and Increased Freshwater Input on the Stratification and Sea Ice Cover in a Changing Arctic Ocean, J. Phys. Oceanogr., 46, 1531-1553, doi:10.1175/jpo-d-15-0174.1, 2016.

Dee, D. P., Uppala, S. M., Simmons, A. J., Berrisford, P., Poli, P., Kobayashi, S., Andrae, U., Balmaseda, M. A., Balsamo, G., Bauer, P., Bechtold, P., Beljaars, A. C. M., van de Berg, L., Bidlot, J., Bormann, N., Delsol, C., Dragani, R., Fuentes, M., Geer, A. J., Haimberger, L., Healy, S. B., Hersbach, H., Hólm, E. V., Isaksen, L., Kållberg, P., Köhler, M., Matricardi, M., McNally, A. P., Monge-Sanz, B. M., Morcrette, J.-J., Park, B.-K., Peubey, C., de Rosnay, P., Tavolato, C., Thépaut, J.-N., and Vitart, F.: The ERA-Interim reanalysis: configuration and performance of the data assimilation system, Q. J. Roy. Meteor. Soc., 137, 553-597, doi:10.1002/qj.828, 2011.
Dobrynin, M., Murawsky, J., and Yang, S.: Evolution of the global wind wave climate in CMIP5 experiments, Geophys. Res. Lett., 39, L18606, doi:10.1029/2012g1052843, 2012.

Ezraty, R., Girard-Ardhuin, F., Piolle, J. F., Kaleschke, L., and Heygster, G.: Arctic and Antarctic sea ice concentration and Arctic sea ice drift estimated from Special Sensors Microwave data, User manual version 2.1, Ifremer/CERSAT, ftp.ifremer.fr/ifremer/cersat/products/gridded/ psi-drift/documentation/ssmi.pdf, last access: 5 February 2007.

Francis, O. P., Panteleev, G. G., and Atkinson, D. E.: Ocean wave conditions in the Chukchi Sea from satellite and in situ observations, Geophys. Res. Lett., 38, L24610, doi:10.1029/2011gl049839, 2011.

Frey, K., Moore, G. W. K., Cooper, L. W., and Grebmeier, J. M.: Divergent patterns of recent sea ice cover cross the Bering, Chukchi, and Beaufort seas of the Pacific Arctic Region, Prog. Oceanogr., 136, 32-49, doi:10.1016/j.pocean.2015.05.009, 2015.

Gemmrich, J., Thomas, B., and Bouchard, R.: Observational changes and trends in northeast Pacific wave records, Geophys. Res. Lett., 38, L22601, doi:10.1029/2011g1049518, 2011.

Grant, W. D. and Madsen, O. S.: Combined wave and current interaction with a rough bottom, J. Geophys. Res., 84, 1797-1808, 1979.

Gulev, S. K. and Grigorieva, V.: Variability of the Winter Wind Waves and Swell in the North Atlantic and North Pacific as Revealed by the Voluntary Observing Ship Data, J. Climate, 19, 5667-5685, doi:10.1175/jcli3936.1, 2006.

Hanson, J. L. and Phillips, O. M.: Automated Analysis of Ocean Surface Directional Wave Spectra, J. Atmos. Ocean. Tech., 18, 277-293, doi:10.1175/15200426(2001)018<0277:aaoosd>2.0.co;2, 2001.

Hartmann, D., Tank, A. K., Rusticucci, M., Alexander, L., Bronnimann, S., Charabi, Y., Dentener, F., Dlugokencky, E., Easterling, D., Kaplan, A., Soden, B., Thorne, P., Wild, M., and Zhai, P.: Observations: Atmosphere and Surface. In: Climate Change 2013: The Physical Science Basis, Cambridge University Press, Cambridge, United Kingdom and New York, NY, USA, 2013.

Hirsch, R. M., Slack, J. R., and Smith, R. A.: Techniques of trend analysis for monthly water quality data, Water Resour. Res., 18, 107-121, doi:10.1029/wr018i001p00107, 1982.

Husson, R., Ardhuin, F., Collard, F., Chapron, B., and Balanche, A.: Revealing forerunners on Envisat's wave mode ASAR using the Global Seismic Network, Geophys. Res. Lett., 39, L15609, doi:10.1029/2012g1052334, 2012.

Jeffries, M. O., Overland, J. E., and Perovich, D. K.: The Arctic shifts to a new normal, Phys. Today, 66, 35, doi:10.1063/pt.3.2147, 2013.

Jensen, B. L., Sumer, B. M., and Fredsoe, J.: Turbulent oscillatory boundary layers at high Reynolds numbers, J. Fluid Mech., 206, 265-297, 1989.

Kaleschke, L., Lupkes, C., Vihma, T., Haarpaintner, J., Bochert, A., Hartmann, J., and Heygster, G.: SSM/I Sea Ice Remote Sensing for Mesoscale Ocean-Atmosphere Interaction Analysis, Can. J. Remote Sens., 27, 526-537, doi:10.1080/07038992.2001.10854892, 2001.

Kendall, M.: Rank Correlation Methods, 4th edition, Oxford University Press, 1975. 
Khon, V. C., Mokhov, I. I., Pogarskiy, F. A., Babanin, A., Dethloff, K., Rinke, A., and Matthes, H.: Wave heights in the 21 st century Arctic Ocean simulated with a regional climate model, Geophys. Res. Lett., 41, 2956-2961, doi:10.1002/2014g1059847, 2014.

Kohout, A. L., Williams, M. J. M., Dean, S. M., and Meylan, M. H.: Storm-induced sea-ice breakup and the implications for ice extent, Nature, 509, 604-607, doi:10.1038/nature13262, 2014.

Komen, G. J., Cavaleri, L., Donelan, M., Hasselmann, K., Hasselmann, S., and Janssen, P. A. E. M.: Dynamics and modelling of ocean waves, Cambridge University Press, 1994.

Li, J., Kohout, A. L., and Shen, H. H.: Comparison of wave propagation through ice covers in calm and storm conditions, Geophys. Res. Lett., 42, 5935-5941, doi:10.1002/2015g1064715, 2015.

Liu, A. K. and Cavalieri, D. J.: On sea ice drift from the wavelet analysis of the Defense Meteorological Satellite Program (DMSP) Special Sensor Microwave Imager (SSM/I) data, Int. J. Remote Sens., 19, 1415-1423, doi:10.1080/014311698215522, 1998.

Liu, A. K. and Mollo-Christensen, E.: Wave propagation in a solid ice pack, J. Phys. Oceanogr., 18, 1702-1712, 1988.

Liu, A. K., Holt, B., and Vachon, P. W.: Wave propagation in the marginal ice zone' model predictions and comparisons with buoy and synthetic aperture radar data, J. Geophys. Res., 96, 46054621, 1991.

Madsen, O. S., Mathisen, P. P., and Rosengaus, M. M.: Movable bed friction factors for spectral waves, in: Proceedings of the 22nd international conference on coastal engineering, ASCE, 22, 420429, 1990.

Mann, H. B.: Nonparametric tests against trend, Econometrica, 13, 245-259, http://www.jstor.org/stable/1907187, 1945.

Marko, J. R.: Observations and analyses of an intense waves-inice event in the Sea of Okhotsk, J. Geophys. Res., 108, 3296, doi:10.1029/2001jc001214, 2003.

McPhee, M. G. and Smith, J. D.: Measurements of the turbulent boundary layer under pack ice, J. Phys. Oceanogr., 6, 696-711, 1976.

Overeem, I., Anderson, R. S., Wobus, C. W., Clow, G. D., Urban, F. E., and Matell, N.: Sea ice loss enhances wave action at the Arctic coast, Geophys. Res. Lett., 38, L17503, doi:10.1029/2011gl048681, 2011.

Perignon, Y., Ardhuin, F., Cathelain, M., and Robert, M.: Swell dissipation by induced atmospheric shear stress, J. Geophys. Res., 119, 6622-6630, doi:10.1002/2014JC009896, 2014.

Perovich, D.: The Changing Arctic Sea Ice Cover, Oceanography, 24, 162-173, doi:10.5670/oceanog.2011.68, 2011.

Pierson, W. J. and Moskowitz, L.: A proposed spectral form for fully developed wind seas based on the similarity theory of S. A. Kitaigorodskii, J. Geophys. Res., 69, 5181-5190, doi:10.1029/jz069i024p05181, 1964.

Popova, E. E., Yool, A., Coward, A. C., Aksenov, Y. K., Alderson, S. G., de Cuevas, B. A., and Anderson, T. R.: Control of primary production in the Arctic by nutrients and light: insights from a high resolution ocean general circulation model, Biogeosciences, 7, 3569-3591, doi:10.5194/bg-7-3569-2010, 2010.

Queffeulou, P. and Croize-Fillon, D.: Global altimeter SWH data set, Technical Report 11.2, IFREMER/CERSAT, ftp://ftp.ifremer.fr/ifremer/cersat/products/swath/altimeters/ waves/documentation/altimeter_wave_merge_11.2.pdf, last access: 15 February 2016.
Rascle, N. and Ardhuin, F.: A global wave parameter database for geophysical applications. Part 2: Model validation with improved source term parameterization, Ocean Model., 70, 174188, doi:10.1016/j.ocemod.2012.12.001, 2013.

Reistad, M., Breivik, O., Haakenstad, H., Aarnes, O. J., Furevik, B. R., and Bidlot, J.-R.: A high-resolution hindcast of wind and waves for the North Sea, the Norwegian Sea, and the Barents Sea, J. Geophys. Res., 116, C05019, doi:10.1029/2010jc006402, 2011.

Rogers, E. W. and Orzech, M. D.: Implementation and testing of ice and mud source functions in WAVEWATCH III, Memorandum Report NLR/MR/7320-13-9462, Naval Research Laboratory, http://www7320.nrlssc.navy.mil/pubs.php, 2013.

Saha, S., Moorthi, S., Pan, H.-L., Wu, X., Wang, J., Nadiga, S., Tripp, P., Kistler, R., Woollen, J., Behringer, D., Liu, H., Stokes, D., Grumbine, R., Gayno, G., Wang, J., Hou, Y.-T., Chuang, H.Y., Juang, H.-M. H., Sela, J., Iredell, M., Treadon, R., Kleist, D., Van Delst, P., Keyser, D., Derber, J., Ek, M., Meng, J., Wei, H., Yang, R., Lord, S., Van Den Dool, H., Kumar, A., Wang, W., Long, C., Chelliah, M., Xue, Y., Huang, B., Schemm, J.-K., Ebisuzaki, W., Lin, R., Xie, P., Chen, M., Zhou, S., Higgins, W., Zou, C.-Z., Liu, Q., Chen, Y., Han, Y., Cucurull, L., Reynolds, R. W., Rutledge, G., and Goldberg, M.: The NCEP Climate Forecast System Reanalysis, B. Am. Meteorol. Soc., 91, 1015-1057, doi:10.1175/2010bams3001.1, 2010.

Saha, S., Moorthi, S., Wu, X., Wang, J., Nadiga, S., Tripp, P., Behringer, D., Hou, Y.-T., Chuang, H.-y., Iredell, M., Ek, M., Meng, J., Yang, R., Mendez, M. P., van den Dool, H., Zhang, Q., Wang, W., Chen, M., and Becker, E.: The NCEP Climate Forecast System Version 2, J. Climate, 27, 2185-2208, doi:10.1175/jcli-d-12-00823.1, 2014.

Screen, J. A. and Simmonds, I.: The central role of diminishing sea ice in recent Arctic temperature amplification, Nature, 464, 1334-1337, doi:10.1038/nature09051, 2010.

Semedo, A., Sušelj, K., Rutgersson, A., and Sterl, A.: A Global View on the Wind Sea and Swell Climate and Variability from ERA-40, J. Climate, 24, 1461-1479, doi:10.1175/2010jcli3718.1, 2011.

Semedo, A., Vettor, R., Breivik, O., Sterl, A., Reistad, M., Soares, C. G., and Lima, D.: The wind sea and swell waves climate in the Nordic seas, Ocean Dynam., 65, 223-240, doi:10.1007/s10236014-0788-4, 2014.

Sen, P. K.: Estimates of the Regression Coefficient Based on Kendall's Tau, J. Am. Stat. Assoc., 63, 1379-1389, doi:10.1080/01621459.1968.10480934, 1968.

Sepulveda, H. H., Queffeulou, P., and Ardhuin, F.: Assessment of SARAL/AltiKa Wave Height Measurements Relative to Buoy, Jason-2, and Cryosat-2 Data, Mar. Geod., 38, 449-465, doi:10.1080/01490419.2014.1000470, 2015.

Simmonds, I. and Rudeva, I.: The great Arctic cyclone of August 2012, Geophys. Res. Lett., 39, L23709, doi:10.1029/2012g1054259, 2012.

Smith, M. and Thomson, J.: Scaling observations of surface waves in the Beaufort Sea, Elementa: Science of the Anthropocene, 4, 000097, doi:10.12952/journal.elementa.000097, 2016.

Squire, V.: Of ocean waves and sea-ice revisited, Cold Reg. Sci. Technol., 49, 110-133, doi:10.1016/j.coldregions.2007.04.007, doi:10.1016/j.coldregions.2007.04.007, 2007. 
Squire, V. A., Dugan, J. P., Wadhams, P., Rottier, P. J., and Liu, A. K.: Of Ocean Waves and Sea Ice, Annu. Rev. Fluid Mech., 27, 115-168, doi:10.1146/annurev.fl.27.010195.000555, 1995.

Steele, M., Ermold, W., and Zhang, J.: Arctic Ocean surface warming trends over the past 100 years, Geophys. Res. Lett., 35, L02614, doi:10.1029/2007g1031651, 2008.

Stephenson, S. R., Smith, L. C., and Agnew, J. A.: Divergent longterm trajectories of human access to the Arctic, Nature Climate Change, 1, 156-160, doi:10.1038/nclimate1120, 2011.

Sterl, A. and Caires, S.: Climatology, variability and extrema of ocean waves: the Web-based KNMI/ERA-40 wave atlas, Int. J. Climatol., 25, 963-977, doi:10.1002/joc.1175, 2005.

Stopa, J. E.: Wave hindcast data, available at: ftp://ftp.ifremer.fr/ifremer/ww3/HINDCAST/, December 2015.

Stopa, J. E. and Cheung, K. F.: Intercomparison of wind and wave data from the ECMWF Reanalysis Interim and the NCEP Climate Forecast System Reanalysis, Ocean Model., 75, 65-83, doi:10.1016/j.ocemod.2013.12.006, 2014.

Stopa, J. E., Cheung, K. F., Tolman, H. L., and Chawla, A.: Patterns and cycles in the Climate Forecast System Reanalysis wind and wave data, Ocean Model., 70, 207-220, doi:10.1016/j.ocemod.2012.10.005, 2013a.

Stopa, J. E., Filipot, J.-F., Li, N., Cheung, K. F., Chen, Y.-L., and Vega, L.: Wave energy resources along the Hawaiian Island chain, Renew. Energ., 55, 305-321, doi:10.1016/j.renene.2012.12.030, 2013b.

Stopa, J. E., Ardhuin, F., Babanin, A., and Zieger, S.: Comparison and validation of physical wave parameterizations in spectral wave models, Ocean Model., 103, 2-17, doi:10.1016/j.ocemod.2015.09.003, 2015.

Thomson, J. and Rogers, W. E.: Swell and sea in the emerging Arctic Ocean, Geophys. Res. Lett., 41, 3136-3140, doi:10.1002/2014g1059983, http://dx.doi.org/10.1002/ 2014GL059983, 2014.

Thomson, J., Fan, Y., Stammerjohn, S., Stopa, J., Rogers, W. E., Girard-Ardhuin, F., Ardhuin, F., Shen, H., Perrie, W., Shen, H., Ackley, S., Babanin, A., Liu, Q., Guest, P., Maksym, T., Wadhams, P., Fairall, C., Persson, O., Doble, M., Graber, H., Lund, B., Squire, V., Gemmrich, J., Lehner, S., Holt, B., Meylan, M., Brozena, J., and Bidlot, J.-R.: Emerging trends in the sea state of the Beaufort and Chukchi Seas, Ocean Model., 105, 1-12, doi:10.1016/j.ocemod.2016.02.009, 2016.
Tolman, H. L.: Alleviating the Garden Sprinkler Effect in wind wave models, Ocean Model., 4, 269-289, doi:10.1016/s14635003(02)00004-5, 2002.

Tolman, H. L. and the WAVEWATCH III Development Group: User Manual and system documentation of WAVEWATCH III version 4.18, Technical Note 316, NOAA/NWS/NCEP/MMAB, 2014.

Tolman, H. L., Banner, M. L., and Kaihatu, J. M.: The NOPP operational wave model improvement project, Ocean Model., 70, 2-10, doi:10.1016/j.ocemod.2012.11.011, 2013.

Tremblay, J.-E., Simpson, K., Martin, J., Miller, L., Gratton, Y., Barber, D., and Price, N. M.: Vertical stability and the annual dynamics of nutrients and chlorophyll fluorescence in the coastal, southeast Beaufort Sea, J. Geophys. Res., 113, C07S90, doi:10.1029/2007jc004547, 2008.

Tuomi, L., Kahma, K. K., and Pettersson, H.: Wave hindcast statistics in the seasonseas ice-covered Baltic Sea, Boreal Environ. Res., 16, 451-472, 2011.

Wadhams, P. and Doble, M. J.: Sea ice thickness measurement using episodic infragravity waves from distant storms, Cold Reg. Sci. Technol., 56, 98-101, doi:10.1016/j.coldregions.2008.12.002, 2009.

Wang, X. L. and Swail, V. R.: Changes of Extreme Wave Heights in Northern Hemisphere Oceans and Related Atmospheric Circulation Regimes, J. Climate, 14, 2204-2221, doi:10.1175/15200442(2001)014<2204:coewhi>2.0.co;2, 2001.

Wang, X. L., Feng, Y., Swail, V. R., and Cox, A.: Historical Changes in the Beaufort-Chukchi-Bering Seas Surface Winds and Waves, 1971-2013, J. Climate, 28, 7457-7469, doi:10.1175/jcli-d-150190.1, 2015.

Young, I. R., Zieger, S., and Babanin, A. V.: Global Trends in Wind Speed and Wave Height, Science, 332, 451-455, doi:10.1126/science.1197219, 2011.

Zhang, J.: Warming of the arctic ice-ocean system is faster than the global average since the 1960s, Geophys. Res. Lett., 32, L19602, doi:10.1029/2005g1024216, 2005.

Zhang, J., Lindsay, R., Schweiger, A., and Steele, M.: The impact of an intense summer cyclone on 2012 Arctic sea ice retreat, Geophys. Res. Lett., 40, 720-726, doi:10.1002/grl.50190, 2013.

Zieger, S., Vinoth, J., and Young, I. R.: Joint Calibration of Multiplatform Altimeter Measurements of Wind Speed and Wave Height over the Past 20 Years, J. Atmos. Ocean. Techn., 26, 2549-2564, doi:10.1175/2009jtecha1303.1, 2009. 